DOI: http://dx.doi.org/10.5007/2175-8069.2016v13n30p160

\title{
Relação entre book-tax differences e conservadorismo contábil: um estudo das companhias abertas de países da América Latina
}

\section{Relationship between book-tax differences and accounting conservatism: a study of open companies in Latin American countries}

\section{Relación entre book-tax differences y conservadorismo contábil: un estudio de las compañías abiertas de países de Latino América}

\section{Cassius Klay Silva Santos}

Mestre em Contabilidade e Controladoria na Universidade Federal de Uberlândia Professor do curso de Ciências Contábeis na Fundação Carmelitana Mário Palmério Endereço: Av. Brasil Oeste, s/n, Bairro Jardim Zenith

CEP: 38.500-000 - Monte Carmelo/MG - Brasil

E-mail: cassiusklay@gmail.com

Telefone: (34) 3842-5272

\section{Patrícia de Souza Costa}

Doutora em Controladoria e Contabilidade na Universidade de São Paulo

Professor do curso de Ciências Contábeis da Universidade Federal de Uberlândia

Endereço: Rua João Naves de Ávila, n. 2122, sala 1F215, Bairro Santa Mônica

CEP: 38400-902 - Uberlândia/MG - Brasil

E-mail: patricia.costa@ufu.br

Telefone: (34) 99155-9524

\section{Pablo Rogers Silva}

Doutor em Administração na Universidade de São Paulo

Professor do curso de Gestão e Negócios da Universidade Federal de Uberlândia

Endereço: Rua João Naves de Ávila, n. 2122, sala 1F216, Bairro Santa Mônica

CEP: 38400-902 - Uberlândia/MG - Brasil

E-mail: pablorogers@ufu.br

Telefone: (34) 3239-4132

Artigo recebido em 12/03/2015. Revisado por pares em 23/03/2016. Reformulado em 12/12/2016. Recomendado para publicação em 15/12/2016 por Carlos Eduardo Facin Lavarda (Editor-Chefe). Publicado em 17/12/2016. 
Resumo

O objetivo da presente pesquisa é verificar se existe relação entre o conservadorismo contábil e os tipos de book-tax differences (BTD). A amostra é composta por companhias abertas listadas em cinco países latino-americanos no período 2004 a 2013. A análise foi realizada com a modificação e a aplicação do modelo de Basu (1997). Pelos resultados deste estudo, compreende-se que a BTD, nos formatos total, temporário, permanente, e em valores elevados nos formatos positivo e negativo, informa sobre o conservadorismo em relação aos resultados tributários e financeiros. Para as companhias de países da América Latina, encontrou-se menor relação entre o conservadorismo incondicional e os tipos de BTD, sugerindo que as informações reportadas pelas companhias latino-americanas podem não estar associadas a práticas de gerenciamento de resultado. Quanto ao conservadorismo condicional, não foi identificada relação com os tipos de BTD, o que é esperado para maior qualidade das informações contábeis.

Palavras-chave: Book-tax differences. Lucro Contábil. Lucro Tributável. Conservadorismo Contábil. América Latina.

\begin{abstract}
This research aim is to verify if here is a relationship between accounting conservatism and the types of book-tax differences (BTD). The sample is comprised of public companies listed in five Latin America in the period between 2004 and 2013. The analysis was performed with the modification and application of the Basu (1997) model. The results of this study suggest that all formats of BTD (temporary, permanent, and also at high values to the positive and negative format) provide information on the conservatism regarding taxable income and financial. It was identified that Latin America companies have less unconditional relationship between conservatism and BTD types, suggesting that the information reported by them is not associated with earnings management practices. For the conditional conservatism was not identified higher relation to the types of BTD, that is considering for higher quality for financial information.
\end{abstract}

Keywords: Book-tax differences. Book Income. Taxable Income. Accounting Conservatism. Latin America.

\title{
Resumen
}

El objetivo de esta investigación es determinar si existe una relación entre el conservadorismo contable y los tipos de book-tax differences (BTD). La muestra se compone de compañías abiertas listadas en cinco países latinoamericanos en el período de 2004-2013. El análisis fue realizado con la modificación y aplicación del modelo de Basu (1997). Por los resultados de este estudio, se comprende que las BTD en los formatos total, temporario, permanente, $y$ en valores elevados en los formatos positivos y negativos informan sobre el conservadorismo en relación a los resultados tributarios y financieros. Para las compañías latinoamericanas, se encontró menor relación entre el conservadorismo incondicional y los tipos de BTD, sugiriendo que las informaciones reportadas pueden no estar asociadas a las prácticas de administración de resultados. Cuanto al conservadorismo condicional, no fue identificada mayor relación con los tipos de BTD, lo que es esperado para mayor calidad de las informaciones contables.

Palabras clave: Book tax differences. Resultado Contable. Ingreso Imponible. 


\section{Introdução}

Potenciais benefícios da redução da vinculação entre as normas contábeis e fiscais (também conhecida por conformidade financeira e fiscal - CFF) têm sido debatidos em vários países, principalmente após a adoção das International Financial Reporting Standards (IFRS). O subjetivismo responsável, o aumento das escolhas contábeis e uma menor vinculação entre as normas contábeis e fiscais, aspectos inerentes à adoção das IFRS, conduzem à redução da $\mathrm{CFF}$ e, consequentemente, a uma diferença cada vez maior entre o lucro contábil e o lucro tributável (book-tax differences - BTD). O lucro contábil e o lucro tributável representam o mesmo evento econômico, porém eles são apurados por meio de diferentes normas, resultando na BTD. Enquanto as normas contábeis visam à representação fidedigna e à relevância da informação para o usuário, permitindo, inclusive, escolhas contábeis, as normas fiscais primam pela objetividade e maior arrecadação. Os defensores sugerem que a redução da CFF (aumento da BTD) eleva a qualidade da informação contábil, uma vez que os objetivos das normas contábeis são diferentes dos objetivos das normas fiscais (ATWOOD; DRAKE; MYERS, 2010; WAHAB; HOLLAND, 2015). Os opositores acreditam que a redução da CFF irá aumentar o gerenciamento fiscal e de resultados, reduzindo a qualidade das informações contábeis e aumentando a evasão fiscal (ATWOOD; DRAKE; MYERS, 2010; WAHAB; HOLLAND, 2015).

Um dos aspectos da qualidade da informação contábil relacionado com a BTD é o conservadorismo contábil (HELTZER, 2009). Heltzer (2009) ressalta que a noção de que a BTD revela informações sobre o conservadorismo contábil contido nas demonstrações financeiras não é nova. O tema é tratado em livros didáticos como, por exemplo, o de Revsine, Collins e Johnson (2005), que ensinam que a informação útil, para avaliar o grau de conservadorismo, pode ser extraída das notas explicativas sobre a reconciliação entre o lucro tributável e o lucro contábil, comparando a relação entre o lucro contábil antes do imposto de renda (LAIR) e o lucro tributável. Pratt (2011) assevera que o fato de o LAIR exceder (ou ser menor que) o lucro tributável indica o quão conservador é o resultado divulgado. Esse autor ainda acrescenta que quando a relação entre o LAIR e o lucro tributável é próxima a 1 (um), há indicação de níveis de conservadorismo, enquanto o nível de conservadorismo diminui à medida que essa relação cresce. Assim, essas observações sugerem que quanto maior a BTD menor o conservadorismo contábil.

As relações existentes entre o sistema de tributação e as informações contábeis podem incentivar o conservadorismo, no sentido de buscar reduzir a carga de impostos e melhorar os resultados financeiros por meio da assimetria de reconhecimento de boas e más notícias (WATTS, 2003a). A existência de uma diferença muito elevada entre os resultados pode ser um fato considerado negativo pelo mercado financeiro (HANLON; HEITZMAN, 2010), podendo estimular os gestores a serem mais conservadores com o propósito de reduzir a diferença entre o resultado financeiro e o tributável. Isso pode afetar a qualidade de maneira negativa, uma vez que a diferença seria proveniente do foco aplicado pelo usuário a cada uma das formas de resultado.

Heltzer (2009) analisou a relação entre BTD e conservadorismo baseando-se em uma amostra de 36.165 observações da Compustat para o período de 1994 a 2003. Esse autor verificou que o conservadorismo condicional e o incondicional apresentados nas demonstrações contábeis das empresas com maiores níveis de BTD positiva (LAIR maior do que o lucro tributável) é similar àquele das outras empresas, enquanto o conservadorismo 
condicional e incondicional do lucro tributável das empresas com maiores níveis de BTD positiva (LAIR maior do que o lucro tributável) é maior do que para o restante da amostra. Esse resultado é contrário ao sugerido na literatura (ver PRATT, 2011). Adicionalmente, Heltzer verificou que o conservadorismo incondicional apresentado nas demonstrações contábeis das empresas com maiores níveis de BTD negativa (LAIR menor do que o lucro tributável) é maior do que o conservadorismo presente no restante da amostra e que, ao mesmo tempo, o conservadorismo condicional e incondicional do lucro tributável para as empresas com maiores níveis de BTD negativa é menor que o constatado no restante da amostra. Como o crescimento do conservadorismo das demonstrações financeiras entre as empresas com BTD negativa é de natureza incondicional, o aumento do conservadorismo para a amostra estudada não pode estar relacionado a uma maior qualidade dos lucros.

A pesquisa de Heltzer (2009) é pioneira no estudo da relação entre BTD e conservadorismo contábil. De acordo com os resultados encontrados por esse autor, percebese que a análise segregada por tipos de conservadorismo (condicional e incondicional) e por tipos de BTD é relevante. A BTD pode ser segregada em quatro tipos: positiva (BTDPO), em que o resultado financeiro supera o tributário; negativa (BTDNE), quando o resultado tributário se mostra mais elevado que o financeiro; permanente (BTDP), em que as diferenças entre os resultados são resultantes das particularidades de forma (financeira ou tributária); e temporária, quando os tratamentos pelo sistema financeiro e tributário são os mesmos, mas podem ocorrer em momentos distintos (HELTZER, 2009). Ressalta-se que Heltzer (2009) analisou apenas a relação de dois tipos de BTD (positiva e negativa) com os dois tipos de conservadorismo.

A análise segregada em conservadorismo condicional e incondicional é necessária em virtude das dúvidas existentes na literatura quanto à relação da qualidade contábil com a prática de conservadorismo contábil (HELTZER, 2009). O International Accounting Standards Board (IASB) não considera o conservadorismo (prudência) como característica exigida para práticas contábeis, mesmo sabendo que ele ainda pode estar presente nas demonstrações contábeis. Na concepção do IASB, indicar a prática do conservadorismo (prudência) como requisito para a elaboração dos relatórios contábeis afetaria a neutralidade das informações (IASB, 2011). Esse fato gerou discussão, pois, enquanto profissionais ressaltam que o conservadorismo é intrínseco à contabilidade, outros consideram que o conservadorismo incondicional pode ser prejudicial às informações contábeis (IASB, 2011). Mesmo com a orientação emitida pelo IASB sobre a não utilização de práticas conservadoras, Pham, Shook e Myers (2009), Filipin et al. (2012) e Bertin e Moya (2013) observam aumento do conservadorismo condicional após a adoção das IFRS e, por sua vez, Piot, Dumontier e Janin (2010) e Hou, Jin e Wang (2014) identificaram redução do conservadorismo condicional em relatórios contábeis. Independente do consenso entre os autores sobre a prática do conservadorismo, ressalta-se que ele está presente nos relatórios contábeis após a adoção das IFRS.

Sendo assim, a presente pesquisa tem o objetivo de verificar se há relação entre o nível de conservadorismo contábil e os tipos de BTD evidenciados nos relatórios contábeis das companhias abertas de países da América Latina. A amostra é composta por 600 companhias abertas listadas em cinco países latino-americanos (Argentina, Brasil, Chile, México e Peru), no período entre 2004 e 2013.

Enquanto Heltzer (2009) recorreu a uma amostra de empresas de países common law e code law, esta pesquisa se diferencia por focar em países de origem legalista. Gray (1988) 
verificou que os países latino-americanos comportam empresas cujas práticas contábeis observam alto grau de conservadorismo condicional. Isso foi confirmado por Doupnik e Riccio (2006), ao reaplicarem a pesquisa de Gray (1988), uma vez que esses autores também verificaram maior grau de conservadorismo condicional nos relatórios de companhias latinoamericanas. Dessa forma, os resultados desta pesquisa podem se diferenciar daqueles encontrados por Heltzer 2009). Além disso, nesta pesquisa, será analisada a relação entre cinco tipos de BTD (total, positiva, negativa, temporária e permanente) e os dois tipos de conservadorismo (condicional e incondicional).

Segundo informações do Worldbank (2014), os países latino-americanos são responsáveis por $8 \%$ do valor do Produto Interno Bruto (PIB) de todo o mundo. A amostra utilizada nesta pesquisa (Argentina, Brasil, Chile, México e Peru) representa, dentro do valor referente à América Latina, $77 \%$ da formação do PIB, evidenciando, assim, a relevância econômica dos países em estudo para a América Latina em seu todo. Considerando as alterações proporcionadas pela adoção das IFRS, o cenário latino-americano, com as particularidades de seu sistema legal, culturais e econômicas, mostra ser um ambiente viável para a investigação da relação entre conservadorismo contábil e BTD.

Os resultados desta pesquisa podem contribuir com a literatura, com normatizadores, reguladores e órgãos fiscalizadores na análise da relação entre os níveis de conformidade entre a contabilidade societária e a contabilidade fiscal (representados pelos níveis de BTD) e a qualidade da informação contábil. Espera-se que a identificação da relação entre o conservadorismo e a BTD possa auxiliar os usuários na avaliação das informações contábeis empregadas para a tomada de decisão.

\section{Referencial Teórico}

\subsection{Book-Tax Differences}

A book-tax differences (BTD) é resultante de práticas distintas usadas na apuração do resultado contábil para fins de divulgação aos acionistas (contabilidade financeira) e com a finalidade de cálculo de impostos (contabilidade tributária). Chan, Lin e Mo (2010) e Hanlon e Heitzman (2010) explicam que a BTD pode ser decorrente de três principais causas: a) objetivos naturalmente diferentes entre as normas para a contabilidade financeira e a contabilidade tributária; b) gerenciamento de resultados para a exposição de maiores lucros ao mercado; e c) gerenciamentos fiscais com vista à redução da carga de impostos.

A primeira causa da BTD é o desalinhamento das normas que estipulam a forma de cálculo do resultado tributário e do resultado financeiro (MILLS; PLESKO, 2003; DESAI, 2005; FORMIGONI; ANTUNES; PAULO, 2009; HANLON; MAYDEW, 2009). A diferença de finalidade entre essas normas contribui para que haja regras que sejam aplicadas a um tipo de resultado, mas não ao outro. Enquanto o objetivo principal do resultado apurado pela contabilidade financeira é informar o mercado sobre a situação econômica da empresa, observando a representação fidedigna (HANLON, 2005; CHAN; LIN; MO, 2010; HANLON; HEITZMAN, 2010), a contabilidade tributária está voltada à necessidade de informar as entidades governamentais sobre o pagamento de impostos (WEBER, 2009). Assim, naturalmente, ocorrerá diferença nos valores do lucro contábil e do lucro tributável, uma vez que há propósitos diferentes para o cálculo desses itens. Neste sentido, mesmo que seja utilizada a mesma base contábil para o cálculo dos resultados financeiros e tributáveis, será possível identificar diferenças, pois estas podem ser resultantes de escolhas permitidas por um 
sistema, mas não pelo outro (FORMIGONI; ANTUNES; PAULO, 2009).

A segunda causa das diferenças é que a BTD pode ser resultante do gerenciamento de resultados com o objetivo de elevar o resultado financeiro. Os gestores recorrem a essa prática para apresentar melhores resultados aos acionistas e, ainda assim, não aumentar o custo do pagamento de impostos (HANLON; HEITZMAN, 2010). Para isso, podem manter o cálculo real obtido para pagamentos de tributos, e inflar os resultados financeiros, muitas vezes, aproveitando-os.

A BTD também pode ser resultante do gerenciamento por parte dos gestores visando à redução do resultado tributário, sendo esta a terceira causa da BTD. Alternativamente, os gestores podem reduzir o resultado tributário de forma mais expressiva, com mínima alteração do resultado financeiro. Esta prática visaria reduzir o montante a ser tributado, constituindo-se numa evasão fiscal realizada com o objetivo de reduzir o montante pago em impostos e taxas ao governo (HANLON; HEITZMAN, 2010).

Dentre as possíveis classificações para a BTD, podem ser consideradas as formas permanente ou temporária. Na concepção de Hanlon (2005), a BTD permanente (BTDP) se refere aos itens que são assimilados pelos sistemas de cálculo financeiro ou tributário, mas não são considerados para o outro sistema. Portanto, a BTDP pode ser entendida como consequência de uma métrica que impacta o cálculo do resultado financeiro, mas não tem impacto sobre o resultado tributário, ou vice-versa.

Por outro lado, a BTD classificada como temporária (BTDTE) decorre do momento de exigência de reconhecimento do evento econômico por um ou outro sistema (HANLON, 2005; COMPRIX; GRAHAM; MOORE, 2011). Por exemplo, no sistema financeiro é possível haver maior flexibilidade para determinar o tempo de reconhecimento de uma despesa de amortização ou depreciação, enquanto que, no sistema de apuração do resultado tributário, pode ser estipulado por meio de regras o período máximo para o reconhecimento (HANLON, 2005; COMPRIX; GRAHAM; MOORE, 2011). Outro exemplo é a BTDTE resultante de receitas, pois uma receita que é reconhecida pela apuração da forma contábil a partir do reconhecimento de uma despesa equivalente pode ser reconhecida pelo sistema tributário somente após a efetiva entrada da quantia em caixa (HANLON, 2005), resultando assim em uma diferença temporal entre os valores do lucro contábil e do lucro tributável.

O imposto diferido é uma das proxies mais utilizadas na literatura para representar o cálculo da BTDTE (PHILLIPS; PINCUS; REGO, 2003; HANLON, 2005; WEBER, 2009; COMPRIX; GRAHAM; MOORE, 2011; TANG; FIRTH, 2011), pois o montante que foi reconhecido em um dos sistemas, em um momento atual, pode ser absorvido, ao longo de períodos futuros, pelo outro sistema (COMPRIX; GRAHAM; MOORE, 2011).

Outra forma de analisar a BTD é por meio da sua separação em BTD negativa (BTDNE) e BTD positiva (BTDPO). A BTDPO é assim classificada quando, ao avaliar o resultado financeiro e o tributário, o montante correspondente ao resultado financeiro for maior do que o resultado tributário, e se nessa situação houver um excedente de valor financeiro (HANLON, 2005; HELTZER, 2009; KVAAL; NOBES, 2010). Em oposição a isso, a BTDNE ocorre quando se configurar excesso no resultado tributário quando comparado ao resultado financeiro obtido (HANLON, 2005; HELTZER, 2009; KVAAL; NOBES, 2010).

\subsection{Conservadorismo Contábil}

Basu (1997, p. 4, tradução nossa) define o conservadorismo como sendo o lucro 
"refletindo as más notícias mais rapidamente que as boas notícias". O termo conservadorismo, também denominado prudência, refere-se ao reconhecimento das despesas antecipadamente, com maior frequência que a antecipação dos ganhos. Na concepção de Basu (1997), isso faz com que os contadores tenham tendência a exigir maior rigor na avaliação das boas notícias, antes do seu reconhecimento, do que na avaliação das más notícias. Essa assimetria na exigência de verificação dos eventos econômicos futuros está associada aos diferentes níveis de retorno dos participantes, evitando o pagamento de bonificações indevidas a gestores (WATTS, 2003a). A exigência de maior verificação sobre a possibilidade da ocorrência de eventos futuros coíbe as práticas oportunistas dos gestores, evidenciando um aspecto positivo do conservadorismo (WATTS, 2003a, 2003b). No estudo realizado por Basu (1997), foi incluída uma nova concepção de conservadorismo. Basu (1997) propõe a classificação do conservadorismo contábil de duas formas: uma conceituando-o como benéfico para a qualidade das informações contábeis, denominado "conservadorismo condicional"; e outra forma em que sua presença deteriora a qualidade da informação, intitulada "conservadorismo incondicional". A segregação proposta por Basu (1997) estimulou a realização de mais pesquisas relacionadas ao tema (AMARAL; RICCIO; SAKATA, 2012).

O conservadorismo condicional é capaz de agregar maior qualidade às informações contábeis por ser composto por informações tempestivas e com alto grau de verificação, o que facilita e oferece segurança para os usuários que dispõem delas para a tomada de decisão (BASU, 2009). O conservadorismo condicional também proporciona maior grau de eficiência aos contratos, em razão do menor risco de manipulação nesta modalidade (BEAVER; RYAN, 2005; IATRIDIS, 2011). Neste contexto, o conservadorismo condicional proporciona maior qualidade aos relatórios, visto que as informações podem ser percebidas em tempo hábil e são confiáveis.

Por outro lado, o conservadorismo incondicional tem efeito negativo sobre a qualidade da informação contábil e não proporciona o reconhecimento oportuno das informações (BALL; KOTHARI; NIKOLAEV, 2013). Ball e Shivakumar (2005) e Basu (2005) ainda argumentam que, geralmente, o conservadorismo incondicional está associado a práticas de gerenciamento contábil. Portanto, a qualidade das informações contábeis pode variar de acordo com o tipo de conservadorismo identificado.

A exclusão de práticas conservadoras na contabilidade poderia resultar em maiores custos para os investidores e na mudança do comportamento dos gestores (WATTS, 2003a, 2003b). Além disso, o fato de o conservadorismo não estar presente nas práticas contábeis abre margem para os gestores se exporem a mais riscos e serem menos cautelosos. Logo, os gestores estarão mais vulneráveis a enfrentar ações judiciais (WATTS, 1993).

A regulação, assim como os aspectos culturais, tem capacidade de afetar o nível de conservadorismo aplicado na contabilidade das empresas em cada país, tornando-o mais ou menos conservador. Gray (1998) considera que isso é possível por um país ter características próprias sobre o que é aplicado na prática contábil. Sendo assim, questões de regulamentação e regras contábeis fazem com que exista conservadorismo em níveis diferentes.

Após o surgimento das IFRS, o conservadorismo não é entendido como uma das características qualitativas, conforme ressalta o Comitê de Pronunciamento Contábil (CPC, 2011, p. 3), informando que a "característica prudência (conservadorismo) foi retirada da condição de aspecto da representação fidedigna por ser inconsistente com a neutralidade". Nas bases para conclusões (IASB, 2011), é possível identificar divergências quanto à retirada do conservadorismo (prudência) como uma das orientações para a elaboração dos relatórios 
contábeis por parte dos usuários. Isso faz com que ocorram discussões sobre o conservadorismo contábil, em que é debatido se a prática melhora ou prejudica a informação contábil.

No entanto, após a orientação para a subtração dessa característica como necessária para que as informações contábeis tenham qualidade, alguns autores (AHMED; HENRY, 2012; GARBRECHT et al., 2012; ANDRÉ; FILIP; PAUGAM, 2013) ainda constataram conservadorismo nas demonstrações contábeis. Doupnik e Riccio (2006) consideram que algumas normas do IASB (por exemplo, IAS 37; IAS 18 e IAS 11) estão dotadas de elementos conservadores, mesmo com o argumento do próprio emissor de que elas ferem a neutralidade. Desta forma, entende-se que o conservadorismo continua sendo praticado e pode estar presente nos relatórios contábeis.

O argumento de Doupnik e Riccio (2006) é reforçado por Bertin e Moya (2013), que identificam aumento no conservadorismo de companhias chilenas após a adoção das IFRS. Os resultados encontrados revelam que as companhias chilenas evidenciavam características de práticas conservadoras em seus relatórios contábeis com a aplicação das normas locais, e que após a adoção das IFRS, as práticas se revelaram mais presentes. Bertin e Moya (2013) explicam que, independentemente das normas aplicadas, as companhias do Chile demonstraram tendências conservadoras ao elaborar seus relatórios contábeis.

Entretanto, Piot, Dumontier e Janin (2011) observaram que as companhias europeias demostraram redução no nível de conservadorismo nos relatórios contábeis, após a adoção das normas internacionais. Isso evidencia que, para o contexto europeu, a tendência é que as companhias passem a revelar características conservadoras em menor quantidade nos relatórios divulgados, quando comparados aos períodos pré-adoção das IFRS. Desta maneira, percebe-se que não é possível determinar se as IFRS inibem de maneira efetiva o conservadorismo, visto que há resultados diferentes quando se faz análise de demonstrativos contábeis antes e após a adoção das normas internacionais de contabilidade.

\subsection{Conservadorismo Contábil, Book-Tax Differences e Hipóteses de Pesquisa}

A existência da BTD favorece a melhor qualidade das informações reportadas, o que pode ser associado à maior capacidade de fornecer informações realistas sobre a condição econômica da empresa (ATWOOD; DRAKE; MYERS, 2010). Gestores que demonstram maior conformidade entre os resultados, proveniente de imposições legais, tendem a ter menor qualidade nos lucros, pois o gestor sente-se limitado ao expor as informações econômicas e financeiras, ao contrário das companhias com maior diferença, que divulgam relatórios mais informativos (HANLON; MAYDEW; SHEVLIN, 2008).

Ball e Shivakumar (2005) expõem que relatórios com melhor qualidade podem estar relacionados à presença do conservadorismo contábil, pois se espera que tenham reconhecimento oportuno das perdas. A maior qualidade também pode ser creditada ao fato de o conservadorismo condicional estar associado à maior possibilidade de relatar informações de forma eficiente (BEAVER; RYAN, 2005), o que pode auxiliar na tomada de decisão dos usuários. Por outro lado, o conservadorismo incondicional é mais relacionado a práticas gerenciais e outras técnicas que possam interferir na realidade empresarial e prejudicar a informação reportada (WATTS, 2003a; BASU, 2005).

Assim, partindo do pressuposto de que a BTD e o conservadorismo condicional favorecem a qualidade das informações contábeis, há maior possibilidade do conservadorismo condicional estar relacionado positivamente com a BTD. Desta forma, têm-se as duas

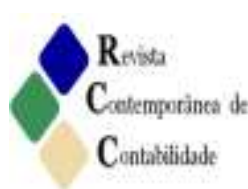


primeiras hipóteses de pesquisa:

$\mathrm{H}_{1}$ : As companhias listadas nas bolsas de valores de países da América Latina apresentam relação positiva entre a BTD e o conservadorismo condicional.

$\mathrm{H}_{2}$ : As companhias listadas nas bolsas de valores de países da América Latina apresentam relação negativa entre a BTD e o conservadorismo incondicional.

A BTDTE pode ser decorrente de ações oportunistas dos gestores (HANLON, 2005). Isso pode ocorrer em consequência do ativo diferido ser proveniente de diferentes escolhas a que os gestores podem recorrer no processo de cálculo dos resultados (COMPRIX; GRAHAM; MOORE, 2001; HANLON, 2005). Desta forma, tendendo a ser uma informação com maior possibilidade de gerenciamento discricionário, tem-se a possibilidade de que esta forma de BTD esteja relacionada ao conservadorismo incondicional, motivando as seguintes hipóteses:

$\mathrm{H}_{3}$ : As companhias listadas nas bolsas de valores de países da América Latina apresentam relação positiva entre a BTDTE e o conservadorismo incondicional.

$\mathrm{H}_{4}$ : As companhias listadas nas bolsas de valores de países da América Latina apresentam relação negativa entre a BTDTE e o conservadorismo condicional.

A BTDP, normalmente, não está associada à presença de comportamento oportunista (HANLON, 2005; COMPRIX; GRAHAM; MOORE, 2011). Estima-se que a BTDP ocorra naturalmente, sendo proveniente das diferenças existentes entre as formas de cálculo dos resultados financeiros e tributários. Neste sentido, a BTDP estaria relacionada ao conservadorismo condicional de forma positiva, e de maneira negativa com $\mathrm{o}$ conservadorismo incondicional, conforme especificado nas hipóteses $\mathrm{H}_{5}$ e $\mathrm{H}_{6}$ :

$\mathrm{H}_{5}$ : As companhias listadas nas bolsas de valores de países da América Latina apresentam relação positiva entre a BTDP e o conservadorismo condicional.

$\mathrm{H}_{6}$ : As companhias listadas nas bolsas de valores de países da América Latina apresentam relação negativa entre a BTDP e o conservadorismo incondicional.

Para a BTDPO e a BTDNE, a situação encontrada por Hanlon (2005) é a de que, independentemente de a BTD ser considerada negativa ou positiva, nas companhias que evidenciaram maior diferença, no sentido de magnitude, foi notada perda na qualidade informacional. As companhias observadas foram separadas em dois grupos, as denominadas como large positive BTD (LPBTD), i.e., empresas com resultados financeiros muito superiores aos resultados tributários; e as large negative BTD (LNBTD), i.e., aquelas cujos resultados tributários são muito superiores aos resultados financeiros. Constatou-se que essas companhias com níveis extremos de BTD tiveram redução da qualidade informacional, possivelmente associada a práticas de gerenciamento dos resultados (HANLON, 2005).

Situação próxima foi encontrada no mercado brasileiro, em que os gestores tendem a manter o saldo da BTD mais linear e próximo de zero, independentemente de serem BTDPO ou BTDNE. Essa ação é praticada por ser considerado que a BTD com valores elevados represente baixa qualidade das informações contábeis (FERREIRA et al., 2012). Heltzer (2009) também identificou comportamentos divergentes nas LPBTD e LNBTD, assumindo 
que elas possam estar associadas positivamente a níveis mais elevados de conservadorismo. Em situação em que são associadas ao resultado tributário ou financeiro, podem manifestar maiores níveis de conservadorismo incondicional. Sendo assim, têm-se as hipóteses $\mathrm{H}_{7}, \mathrm{H}_{8}$, $\mathrm{H}_{9}$ e $\mathrm{H}_{10}$ a serem testadas:

$\mathrm{H}_{7}$ : As companhias listadas nas bolsas de valores de países da América Latina apresentam relação positiva entre as LPBTD e o conservadorismo incondicional.

$\mathrm{H}_{8}$ : As companhias listadas nas bolsas de valores de países da América Latina apresentam relação negativa entre as LPBTD e o conservadorismo condicional.

$\mathrm{H}_{9}$ : As companhias listadas nas bolsas de valores de países da América Latina apresentam relação positiva entre as LNBTD e o conservadorismo incondicional.

$\mathrm{H}_{10}$ : As companhias listadas nas bolsas de valores de países da América Latina apresentam relação negativa entre as LNBTD e o conservadorismo condicional.

No Quadro 1, são arroladas as hipóteses que serão investigadas na pesquisa, bem como os autores que as sustentam para a investigação.

\section{Quadro 1 - Resumo das hipóteses}

\begin{tabular}{|c|c|}
\hline Hipótese investigada & Principais pesquisas \\
\hline $\begin{array}{l}\mathrm{H}_{1} \text { : As companhias listadas nas bolsas de valores de países da América Latina } \\
\text { apresentam relação positiva entre a BTD e o conservadorismo condicional. }\end{array}$ & \multirow{2}{*}{$\begin{array}{l}\text { Atwood; Drake; Mayers } \\
\text { (2010). Hanlon; Maydew; } \\
\text { Shevlin (2008). Ball; } \\
\text { Shivakumar (2005) }\end{array}$} \\
\hline $\begin{array}{l}\mathrm{H}_{2} \text { : As companhias listadas nas bolsas de valores de países da América Latina } \\
\text { apresentam relação negativa entre a BTD e o conservadorismo incondicional. }\end{array}$ & \\
\hline $\begin{array}{l}\mathrm{H}_{3} \text { : As companhias listadas nas bolsas de valores de países da América Latina } \\
\text { apresentam relação positiva entre a BTDTE e o conservadorismo incondicional. }\end{array}$ & \multirow{2}{*}{$\begin{array}{l}\text { Hanlon }(2005) \\
\text { Comprix, Graham e } \\
\text { Moore }(2011)\end{array}$} \\
\hline $\begin{array}{l}\mathrm{H}_{4} \text { : As companhias listadas nas bolsas de valores de países da América Latina } \\
\text { apresentam relação negativa entre a BTDTE e o conservadorismo condicional. }\end{array}$ & \\
\hline $\begin{array}{l}\mathrm{H}_{5} \text { : As companhias listadas nas bolsas de valores de países da América Latina } \\
\text { apresentam relação positiva entre a BTDP e o conservadorismo condicional. }\end{array}$ & \multirow{2}{*}{$\begin{array}{l}\text { Hanlon }(2005) \\
\text { Comprix, Graham e } \\
\text { Moore }(2011)\end{array}$} \\
\hline $\begin{array}{l}\mathrm{H}_{6} \text { : As companhias listadas nas bolsas de valores de países da América Latina } \\
\text { apresentam relação negativa entre a BTDP e o conservadorismo incondicional. }\end{array}$ & \\
\hline $\begin{array}{l}\text { H7: As companhias listadas nas bolsas de valores de países da América Latina } \\
\text { apresentam relação positiva entre as LPBTD e o conservadorismo } \\
\text { incondicional. }\end{array}$ & \multirow{4}{*}{$\begin{array}{l}\text { Hanlon (2005) } \\
\text { Ferreira et al.(2012). } \\
\text { Heltzer (2009) }\end{array}$} \\
\hline $\begin{array}{l}\mathrm{H}_{8}: \text { As companhias listadas nas bolsas de valores de países da América Latina } \\
\text { apresentam relação negativa entre as LPBTD e o conservadorismo condicional. }\end{array}$ & \\
\hline $\begin{array}{l}\mathrm{H}_{9} \text { : As companhias listadas nas bolsas de valores de países da América Latina } \\
\text { apresentam relação positiva entre as LNBTD e o conservadorismo } \\
\text { incondicional. }\end{array}$ & \\
\hline $\begin{array}{l}\mathrm{H}_{10} \text { : As companhias listadas nas bolsas de valores de países da América Latina } \\
\text { apresentam relação negativa entre as LNBTD e o conservadorismo condicional. }\end{array}$ & \\
\hline
\end{tabular}

Fonte: elaborado pelos autores

\section{Metodologia da Pesquisa}

A pesquisa é do tipo descritiva, com abordagem quantitativa. A amostra desta pesquisa é composta por companhias abertas listadas na bolsa de valores de países membros da América Latina. $\mathrm{O}$ critério utilizado, inicialmente, para selecionar os países participantes foi a verificação da adoção das IFRS de forma obrigatória e total até o ano de 2012 (QUADRO 2).

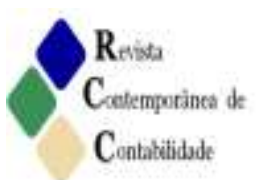


Recorreu-se a esse critério para maior homogeneidade da amostra e ser possível realizar comparações entre os resultados pré e pós-adoção. Nesta condição, dos 21 (vinte e um) países integrantes da América Latina, 8 (oito) deles não correspondiam ao solicitado (QUADRO 2). Entre os 13 (treze) países que restaram, 8 (oito) não disponibilizavam dados na Economática ${ }^{\circledR}$. Desta forma, a amostra final é composta por 5 (cinco) países, sendo eles: Argentina, Brasil, Chile, México e Peru.

Quadro 2 - Países da América Latina e adoção total das IFRS

\begin{tabular}{|l|c|l|c|l|c|}
\hline \multicolumn{1}{|c|}{ País } & Ano de Adoção & \multicolumn{1}{c|}{ País } & Ano de Adoção & \multicolumn{1}{c|}{ País } & Ano de Adoção \\
\hline Argentina & 2012 & El Salvador & 2012 & Nicarágua & Não \\
\hline Bolívia & Não & Equador & 2010 & Panamá & 2000 \\
\hline Brasil & 2010 & $\begin{array}{l}\text { Guiana } \\
\text { Francesa }\end{array}$ & 2010 & Paraguai & Não \\
\hline Chile & 2010 & Guatemala & Não & Peru & 2010 \\
\hline Colômbia & Não & Haiti & Não & $\begin{array}{l}\text { República } \\
\text { Dominicana }\end{array}$ & Não \\
\hline Costa Rica & 2002 & Honduras & 2012 & Uruguai & 2012 \\
\hline Cuba & Não & México & 2012 & Venezuela & 2008 \\
\hline
\end{tabular}

Fonte: elaborado pelos autores de acordo com IFRS (2014) e Worldbank (2014).

A amostra final da pesquisa é composta por 600 companhias abertas (TABELA 1). Para obter esse número, foram excluídas as companhias pertencentes ao setor financeiro, procedimento realizado por serem empresas com regulação própria, o que poderia prejudicar a análise dos dados (LI, 2010; BRAGA, 2013). Também foram desconsideradas as empresas que não divulgavam dados para nenhuma das variáveis ou não os tinham, para, no mínimo, três anos nas variáveis dependentes.

Tabela 1 - Número de empresas que compõem a amostra

\begin{tabular}{l|r|r|r|r}
\hline \multicolumn{1}{c|}{ Países } & $\begin{array}{c}\text { Companhias } \\
\text { Disponíveis }\end{array}$ & $\begin{array}{c}\text { Exclusão setor } \\
\text { financeiro }\end{array}$ & $\begin{array}{c}\text { Exclusão por falta } \\
\text { de dados }\end{array}$ & $\begin{array}{c}\text { Total de companhias } \\
\text { válidas }\end{array}$ \\
\hline Argentina & 204 & 10 & 144 & 50 \\
Brasil & 719 & 67 & 341 & 278 \\
Chile & 409 & 47 & 264 & 98 \\
México & 413 & 93 & 216 & 93 \\
Peru & 306 & 67 & 172 & 61 \\
\hline Total & 2.051 & 284 & 1.137 & 600 \\
\hline
\end{tabular}

Fonte: dados da pesquisa.

As informações coletadas correspondem ao período de 2004 a 2013. Todos os dados foram coletados na base de dados Economática ${ }^{\circledR}$, com exceção da variável de Imposto de Renda Diferido (IDR), que foi obtida na base S\&P Capital IQ-McGRAW®. Como cada país trabalha com uma moeda própria, optou-se pela coleta com base em uma moeda comum, utilizando-se como moeda única o dólar americano.

Cabe ressaltar que os dados obtidos são provenientes de demonstrações consolidadas, e para as companhias que possuíam mais de um tipo de ação negociada em bolsa, foram selecionadas as informações de maior liquidez.

Para a realização do cálculo das book-tax differences totais (BTD), permanentes 
$(B T D T P)$ e temporárias (BTDTE), foram empregadas, respectivamente, as Equações 1, 2 e 3. As fórmulas aplicadas nesta pesquisa são baseadas em estudos anteriores desenvolvidos por Frank, Lynch e Rego (2009) (não constam nas Referências), Wilson (2009) (não consta nas Referências), Comprix, Graham e Moore (2011) e Costa e Lopes (2015).

$$
\begin{array}{cc}
\mathrm{BTD}_{\mathrm{it}}=\frac{\left(\mathrm{LAIR}_{\mathrm{it}}-\mathrm{LT}_{\mathrm{it}}\right)}{\mathrm{P}_{\mathrm{it}-1}} & \text { Equação (1) } \\
\mathrm{BTDP}_{\mathrm{it}}=\mathrm{BTD}_{\mathrm{it}}-\mathrm{BTDTE}_{\mathrm{it}} & \text { Equação (2) } \\
\mathrm{BTDTE}_{\mathrm{it}}=\frac{\left(\mathrm{IRD}_{\mathrm{it}} \div \mathrm{A}_{\mathrm{t}}\right)}{\mathrm{P}_{\mathrm{it}-1}} & \text { Equação (3) }
\end{array}
$$

A variável $B T D$ representa diferença total; $L A I R$ é o lucro contábil antes do imposto de renda; $L T$ corresponde ao lucro tributável; $P$ corresponde ao preço da ação $i$ no ano $t-1$; $B T D P$ representa a $B T D$ permanente; $B T D T E$ representa a $B T D$ temporária; $I R D$ é o imposto de renda diferido; $A$ é a alíquota máxima de imposto de renda.

A alíquota máxima de imposto de renda $(A)$ foi especificada para cada país da amostra com base em informações disponíveis na Economática ${ }^{\circledR}$. As alíquotas máximas são: Argentina (35\%), Brasil (34\%), Chile (20\%), México (34\%) e Peru (30\%). O cálculo do lucro tributável (Equação 4) foi feito com base na metodologia aplicada por Lev e Nissin (2004), Hanlon (2005), Costa e Lopes, (2015) e Nakao (2012).

$$
L T_{\text {it }}=\frac{I R C_{\text {it }}}{A_{\text {it }}}
$$

Equação (4)

O lucro tributável $(L T)$ é resultado da razão entre o imposto de renda corrente (IRC) e a alíquota máxima do imposto de renda $(A)$. A necessidade de obter o LT por meio da Equação 4 é devida ao fato de as companhias listadas nos países que fazem parte da amostra estudada não divulgarem de forma pública esse dado. Sendo assim, é realizada uma estimativa sobre o valor, baseando-se nos dados que são disponibilizados pelas companhias. A utilização dessa proxy é decorrente do fato de, em outras pesquisas, por exemplo, Lev e Nissin (2004), Hanlon (2005), Nakao (2012) e Costa e Lopes (2015), já ter sido aplicada.

Utilizando a Equação 1, é possível identificar a BTD positiva (BTDPO) e a negativa (BTDNE). As BTDPO surgem quando o LAIR é maior do que o lucro tributável. Caso o lucro tributável seja maior que o lucro contábil (LAIR < LT), tem-se a BTDNE.

Para testar a relação entre a BTD positiva e a negativa e o conservadorismo contábil dos relatórios financeiros recorreu-se ao modelo especificado por Heltzer (2009). Esse autor modificou o modelo original de Basu (1997), especificado na Equação 5, testando o modelo especificado na Equação 6.

$$
\frac{X_{i t}}{P_{i t-1}}=\alpha_{0}+\alpha_{1} D R E T_{i t}+\alpha_{2} R E T_{i t}+\alpha_{3} D R E T_{i t} R E T_{i t} \quad \text { Equação (5) }
$$

As variáveis que integram o modelo apresentado na Equação 5 são: $X$ é o resultado 
contábil (lucro ou prejuízo) por ação; $P_{i t-1}$ representa o preço da ação da empresa $i$ no ano $t$ 1; RE7 é o retorno econômico da ação, deflacionado pelo valor da ação no período inicial; DRET representa a aplicação de dummy, atribuindo valor igual a 1 para $R E T$ negativo e valor zero para as demais situações.

Heltzer (2009) modificou o modelo especificado na Equação 5 com o propósito de relacionar BTD positiva e negativa e conservadorismo em um mesmo modelo econométrico (Equação 6).

$$
\begin{aligned}
& \frac{X_{\text {it }}}{P_{\text {it }-1}}=\alpha_{0}+\alpha_{1} \text { DRET }_{\text {it }}+\alpha_{2} \text { RET }_{\text {it }}+\alpha_{3} \text { DRET }_{\text {it }} \text { RET }_{\text {it }}+\alpha_{4} \text { LPBTD }_{\text {it }}+\alpha_{5} \text { LNBTD }_{\text {it }}+\alpha_{6} \text { LPBTD }_{\text {it }} \text { DRET }_{\text {it }} \\
& +\alpha_{7} \text { LNBTD }_{\text {it }} \text { DRET }_{\text {it }}+\alpha_{8} \text { LPBTD }_{\text {it }} \text { RET }_{\text {it }}+\alpha_{9} \text { LNBTD }_{\text {it }} \text { RET }_{\text {it }}+\alpha_{10} \text { LPBTD }_{\text {it }} \text { DRET }_{\text {it }} \text { RET }_{\text {it }} \\
& +\alpha_{11} \text { LNBTD }_{\text {it }} \text { DRET }_{\text {it }} \text { RET }_{\text {it }}
\end{aligned}
$$

A variável X representa o resultado da companhia (proxies para lucro contábil (LAIR) ou lucro tributável); $L P B T D$ é uma variável binária, com valor igual a 1, quando são constatados os valores mais altos de BTDPO (último quintil); ${ }^{L N B T D}$ é uma variável igual a 1 quando se têm os valores mais elevados para a BTDNE (primeiro quintil).

Por meio da Equação 6, são testadas as hipóteses H7, H8, H9 e H10. São esperados sinais negativos para as variáveis $\alpha 5$ e $\alpha 6$, e sinal positivo para os coeficientes $\alpha 3$, $\alpha 4$ e $\alpha 10$, atendendo às especificações registradas nas hipóteses.

Tendo como base o modelo apresentado por Heltzer (2009) na Equação 6, substituemse a BTDPO e BTDNE pela BTD total (Equação 7), temporária (BTDTE) e permanente (BTDTP), conforme especificado na Equação 8.

$$
\begin{aligned}
& \frac{X_{\text {it }}}{P_{\text {it }-1}}=\alpha_{0}+\alpha_{1} \text { DRET }_{\text {it }}+\alpha_{2} \text { RET }_{\text {it }}+\alpha_{3} \text { DRET }_{\text {it }} \text { RET }_{\text {it }}+\alpha_{4} \text { BTD }_{\text {it }}+\alpha_{5} \text { BTD }_{\text {it }} \text { DRET }_{\text {it }}+\alpha_{6} \text { BTD }_{\text {it }} \text { RET }_{\text {it }} \\
& +\alpha_{7} \mathrm{BTD}_{\text {it }} \mathrm{DRET}_{\mathrm{it}} \mathrm{RET}_{\mathrm{it}} \\
& \frac{X_{\text {it }}}{P_{\text {it }-1}}=\alpha_{0}+\alpha_{1} \text { DRET }_{\text {it }}+\alpha_{2} \text { RET it }_{\text {it }}+\alpha_{3} \text { DRET }_{\text {it }} \text { RET }_{\text {it }}+\alpha_{4} \text { BTDP }_{\text {it }}+\alpha_{5} \text { BTDTE }_{\text {it }}+\alpha_{6} \text { BTDP }_{\text {it }} \text { DRET }_{\text {it }} \\
& +\alpha_{7} \text { BTDTE }_{\text {it }} \text { DRET }_{\text {it }}+\alpha_{8} \text { BTDP }_{\text {it }} \text { RET }_{\text {it }}+\alpha_{9} \text { BTDTE }_{i t} \text { RET }_{\text {it }}+\alpha_{10} \text { BTDP }_{\text {it }} \text { DRET }_{\text {it }} \text { RET }_{\text {it }} \\
& +\alpha_{11} \text { BTDTE }_{\text {it }} \text { DRET }_{\text {it }} \text { RET }_{\text {it }}
\end{aligned}
$$

São esperados sinais positivos para os coeficientes $\alpha 3$, $\alpha 4$ e $\alpha 7$ na aplicação da Equação 7, para teste das hipóteses H1 e H2. Com a aplicação da Equação 8, são esperados sinais negativos para os coeficientes $\alpha 5$ e $\alpha 11$, e positivos para os coeficientes $\alpha 3, \alpha 4$ e $\alpha 10$, que são as variáveis de interesse para teste das hipóteses H3, H4, H5 e H6.

Os dados foram especificados em painel. Para identificar qual modelo (POLS, efeitos fixos ou efeitos aleatórios) se ajusta melhor aos dados desta pesquisa, foram utilizados três testes: teste de Chow, teste Lagrange Multiplier (LM) de Breusch-Pagan e teste de Hausman (ver FAVERO et al., 2009 - não constam nas Referências). O teste Chow foi empregado para se decidir entre o modelo de dados em painel com estimador POLS e efeitos fixos. O teste LM de Breusch-Pagan foi realizado para verificar qual modelo adotar entre o modelo POLS e efeitos aleatórios. Por meio do teste de Hausman, foi possível verificar qual modelo, entre 
efeitos fixos e efeitos aleatórios, melhor se adapta à referida pesquisa. Os resultados desses testes sugeriram sempre a mesma escolha para as equações testadas nesta pesquisa, sendo: efeitos fixos para Brasil, Chile, México e América Latina; e efeitos aleatórios para Argentina e Peru.

Para mitigar os efeitos de resíduos heterocedásticos, que foram testados por meio do teste de Breusch-Pagan, os erros-padrão dos modelos foram estimados com matriz de variância-covariância robusta quanto à heterocedasticidade (correção de White). O teste de Durbin-Wu-Hausman aplicado aos dados da pesquisa indicou não haver problemas de endogenia e, por isso, optou-se por modelos em painel estático em detrimento de modelos dinâmicos.

\section{Análise dos Resultados}

Os resultados da pesquisa contêm: 1) a análise descritiva; 2) conservadorismo contábil; 3) a relação entre BTD e conservadorismo; 4) a relação entre BTD permanente e temporária e conservadorismo; 5) a relação entre as LPBTD e $L N B T D$ e o conservadorismo.

\subsection{Análise descritiva}

A análise descritiva dos dados para a América Latina é exibida na Tabela 2. Os dados mostrados na Tabela 2 indicam média negativa para a BTD. Neste sentido, considera-se que os valores do resultado financeiro, de forma geral, são menores que os dos resultados tributários.

Tabela 2 - Estatística Descritiva - Variáveis Contínuas (América Latina)

\begin{tabular}{lrcccccccc}
\hline \multicolumn{1}{c}{ Variável } & Obs. (n) & Média & $\begin{array}{c}\text { Desvio } \\
\text { Padrão }\end{array}$ & Mínimo & Máximo & $\begin{array}{c}\mathbf{1}^{\mathbf{0}} \\
\text { Quartil }\end{array}$ & Mediana & $\begin{array}{c}\mathbf{3}^{\mathbf{0}} \\
\text { Quartil }\end{array}$ & Curtose \\
\hline BTD & 4586 & $-0,0151$ & 0,9375 & $-25,6368$ & 24,2403 & $-0,0203$ & 0,0066 & 0,0592 & 300,0538 \\
BTDTE & 4153 & $-0,0194$ & 0,9184 & $-25,6368$ & 24,2403 & $-0,0006$ & 0,0000 & 0,0284 & 367,2212 \\
BTDTP & 4153 & $-0,0097$ & 0,5134 & $-11,2628$ & 14,0804 & $-0,0248$ & 0,0000 & 0,0195 & 278,2520 \\
LAIR & 4586 & 0,2269 & 1,3461 & $-25,6368$ & 28,4996 & 0,0091 & 0,1029 & 0,2569 & 173,0855 \\
LT & 4586 & 0,2421 & 0,9830 & $-7,7977$ & 27,4873 & 0,0085 & 0,0757 & 0,2035 & 335,6299 \\
RET & 4294 & 0,3542 & 1,1135 & $-0,9372$ & 28,9986 & $-0,1748$ & 0,1512 & 0,5781 & 147,2872 \\
\hline
\end{tabular}

Definição das variáveis: $B T D$ é a diferença entre o LAIR e o LT escalonada pelo valor da ação defasado; BTDTE é a BTD temporária; BTDTP é a BTD permanente; LAIR é o lucro contábil antes do imposto de renda escalonado pelo valor da ação defasado; $L T$ é o lucro tributável escalonado pelo valor da ação defasado; $R E T$ corresponde ao retorno da ação escalonado pelo valor da ação defasado.

Fonte: elaborada pelos autores.

Em valores absolutos, observa-se que os resultados financeiros são menores que os tributários também pelas médias do LAIR e LT, que correspondem a 0,227 e 0,242, respectivamente. No entanto, ao realizar o teste de médias, a hipótese de que as médias das variáveis LT e LAIR sejam iguais não foi rejeitada. A variável BTDTP segue o mesmo comportamento da variável BTD, uma vez que é resultante da diferença entre as variáveis BTD e BTDTE.

Na Tabela 3, é demonstrada a estatística descritiva para os países que fazem parte da amostra (Argentina, Brasil, Chile, México e Peru). 
Cassius Klay Silva Santos, Patrícia de Souza Costa, Pablo Rogers Silva

Tabela 3 - Estatística Descritiva - Variáveis Contínuas por País

\begin{tabular}{|c|c|c|c|c|c|c|c|c|c|c|}
\hline \multicolumn{11}{|c|}{ Argentina } \\
\hline \multirow[b]{2}{*}{ Variável } & \multicolumn{5}{|c|}{ Pré-IFRS (2004-2011) } & \multicolumn{5}{|c|}{ Pós-IFRS (2012 - 2013) } \\
\hline & $\begin{array}{l}\text { Obs. } \\
\text { (n) }\end{array}$ & Média & $\begin{array}{l}\text { Desvio } \\
\text { Padrão }\end{array}$ & Mínimo & Máximo & $\begin{array}{c}\text { Obs. } \\
\text { (n) }\end{array}$ & Média & $\begin{array}{l}\text { Desvio } \\
\text { Padrão }\end{array}$ & Mínimo & Máximo \\
\hline$B T D$ & 365 & $-0,0832$ & 0,5723 & $-5,3179$ & 2,2295 & 92 & 0,0001 & 0,6059 & $-2,2565$ & 4,8714 \\
\hline BTDTE & 110 & $-0,0002$ & 0,0009 & $-0,0074$ & 0,0022 & 72 & $-0,0004$ & 0,0021 & $-0,0162$ & 0,0035 \\
\hline BTDTP & 110 & $-0,0398$ & 0,1331 & $-0,8697$ & 0,2009 & 72 & $-0,0081$ & 0,1806 & $-0,7230$ & 0,7963 \\
\hline LAIR & 365 & 0,4386 & 1,7151 & $-2,6652$ & 25,8406 & 92 & 0,1258 & 0,6990 & $-2,2565$ & 5,3883 \\
\hline $\mathrm{LT}$ & 365 & 0,5217 & 1,8034 & $-1,3713$ & 27,4873 & 92 & 0,1258 & 0,2738 & $-0,5535$ & 1,1999 \\
\hline$R E T$ & 357 & 0,1633 & 0,5657 & $-0,8171$ & 3,1189 & 88 & 0,0925 & 0,4603 & $-0,5655$ & 2,5387 \\
\hline \multicolumn{11}{|c|}{ Brasil } \\
\hline \multirow[b]{2}{*}{ Variável } & \multicolumn{5}{|c|}{ Pré-IFRS (2004 - 2009) } & \multicolumn{5}{|c|}{ Pós-IFRS (2010 - 2013) } \\
\hline & $\begin{array}{l}\text { Obs. } \\
\text { (n) }\end{array}$ & Média & $\begin{array}{l}\text { Desvio } \\
\text { Padrão }\end{array}$ & Mínimo & Máximo & $\begin{array}{l}\text { Obs. } \\
\text { (n) }\end{array}$ & Média & $\begin{array}{l}\text { Desvio } \\
\text { Padrão }\end{array}$ & Mínimo & Máximo \\
\hline$B T D$ & 1.145 & $-0,0449$ & 1,6434 & $-25,6368$ & 24,2403 & 917 & $-0,0300$ & 0,5790 & $-9,8380$ & 4,8583 \\
\hline BTDTE & 1.145 & $-0,0326$ & 1,5886 & $-25,6368$ & 24,2403 & 911 & $-0,0342$ & 0,7604 & $-17,3473$ & 4,9601 \\
\hline BTDTP & 1.145 & $-0,0123$ & 0,6779 & $-11,2628$ & 14,0804 & 911 & 0,0032 & 0,2920 & $-1,9244$ & 7,5093 \\
\hline LAIR & 1.145 & 0,3280 & 2,2009 & $-25,6368$ & 28,4996 & 917 & 0,0637 & 0,6221 & $-9,5860$ & 6,6450 \\
\hline $\mathrm{LT}$ & 1.145 & 0,3729 & 1,4255 & $-5,1539$ & 26,8369 & 917 & 0,0937 & 0,1943 & $-0,2516$ & 3,5914 \\
\hline$R E T$ & 1.069 & 0,7684 & 1,6912 & $-0,9372$ & 28,9986 & 868 & 0,0179 & 0,4776 & $-0,8838$ & 5,2942 \\
\hline \multicolumn{11}{|c|}{ Chile } \\
\hline \multirow[b]{2}{*}{ Variável } & \multicolumn{5}{|c|}{ Pré-IFRS (2004 - 2009) } & \multicolumn{5}{|c|}{ Pós-IFRS (2010 - 2013) } \\
\hline & $\begin{array}{l}\text { Obs. } \\
\text { (n) }\end{array}$ & Média & $\begin{array}{l}\text { Desvio } \\
\text { Padrão }\end{array}$ & Mínimo & Máximo & $\begin{array}{l}\text { Obs. } \\
\text { (n) }\end{array}$ & Média & $\begin{array}{l}\text { Desvio } \\
\text { Padrão }\end{array}$ & Mínimo & Máximo \\
\hline$B T D$ & 475 & 0,0440 & 0,3971 & $-2,9945$ & 6,6036 & 350 & 0,0301 & 0,6320 & $-1,8707$ & 10,4232 \\
\hline BTDTE & 475 & 0,0000 & 0,0002 & $-0,0025$ & 0,0021 & 350 & 0,0000 & 0,0004 & $-0,0024$ & 0,0049 \\
\hline BTDTP & 475 & $-0,0440$ & 0,3972 & $-6,6036$ & 2,9945 & 350 & $-0,0301$ & 0,6321 & $-10,4232$ & 1,8707 \\
\hline LAIR & 475 & 0,1497 & 0,4185 & $-1,7681$ & 6,5957 & 350 & 0,1446 & 0,7113 & $-1,8520$ & 11,3389 \\
\hline LT & 475 & 0,1056 & 0,2497 & $-1,3131$ & 2,6004 & 350 & 0,1146 & 0,3408 & $-1,1252$ & 3,7153 \\
\hline RET & 445 & 0,3405 & 1,0139 & $-0,8479$ & 14,9102 & 324 & 0,1125 & 0,4891 & $-0,9224$ & 3,4625 \\
\hline \multicolumn{11}{|c|}{ México } \\
\hline \multirow[b]{2}{*}{ Variável } & \multicolumn{5}{|c|}{ Pré-IFRS (2004 - 2011) } & \multicolumn{5}{|c|}{ Pós-IFRS (2012 - 2013) } \\
\hline & $\begin{array}{l}\text { Obs. } \\
\text { (n) }\end{array}$ & Média & $\begin{array}{l}\text { Desvio } \\
\text { Padrão }\end{array}$ & Mínimo & Máximo & $\begin{array}{l}\text { Obs. } \\
\text { (n) }\end{array}$ & Média & $\begin{array}{l}\text { Desvio } \\
\text { Padrão }\end{array}$ & Mínimo & Máximo \\
\hline$\overline{\mathrm{BTD}}$ & 619 & $-0,0124$ & 0,5744 & $-10,6649$ & 4,2628 & 146 & $-0,0575$ & 0,4165 & $-2,8336$ & 1,4349 \\
\hline BTDTE & 619 & $-0,0115$ & 0,3438 & $-3,9491$ & 2,9950 & 146 & $-0,0337$ & 0,3214 & $-2,6453$ & 0,9711 \\
\hline BTDTP & 619 & $-0,0009$ & 0,5982 & $-6,7158$ & 4,5963 & 146 & $-0,0237$ & 0,5289 & $-3,8047$ & 3,1001 \\
\hline LAIR & 619 & 0,1513 & 0,8712 & $-13,4437$ & 10,6247 & 146 & $-0,0073$ & 0,4959 & $-3,4943$ & 0,5737 \\
\hline LT & 619 & 0,1637 & 0,7300 & $-7,7977$ & 12,9755 & 146 & 0,0501 & 0,2964 & $-2,6085$ & 1,0822 \\
\hline RET & 577 & 0,2695 & 0,6194 & $-0,9136$ & 4,9695 & 137 & 0,2869 & 0,4547 & $-0,9110$ & 1,8535 \\
\hline \multicolumn{11}{|c|}{ Peru } \\
\hline \multirow[b]{2}{*}{ Variável } & \multicolumn{5}{|c|}{ Pré-IFRS (2004 - 2009) } & \multicolumn{5}{|c|}{ Pós-IFRS (2010 - 2013) } \\
\hline & $\begin{array}{l}\text { Obs. } \\
\text { (n) }\end{array}$ & Média & $\begin{array}{l}\text { Desvio } \\
\text { Padrão }\end{array}$ & Mínimo & Máximo & $\begin{array}{c}\text { Obs. } \\
\text { (n) }\end{array}$ & Média & $\begin{array}{l}\text { Desvio } \\
\text { Padrão }\end{array}$ & Mínimo & Máximo \\
\hline$\overline{B T D}$ & 319 & 0,0729 & 0,2962 & $-1,7743$ & 1,9467 & 158 & 0,0078 & 0,0798 & $-0,2542$ & 0,4410 \\
\hline BTDTE & 177 & $-0,0005$ & 0,0124 & $-0,0890$ & 0,1095 & 148 & $-0,0003$ & 0,0018 & $-0,0132$ & 0,0087 \\
\hline BTDTP & 177 & 0,0554 & 0,2142 & $-0,6347$ & 1,7133 & 148 & 0,0109 & 0,0816 & $-0,2527$ & 0,4452 \\
\hline LAIR & 319 & 0,6036 & 1,1270 & $-1,7743$ & 8,2851 & 158 & 0,1788 & 0,2850 & $-0,4607$ & 2,3786 \\
\hline $\mathrm{LT}$ & 319 & 0,5307 & 1,0251 & $-1,5426$ & 7,4908 & 158 & 0,1711 & 0,2902 & $-0,4606$ & 2,4731 \\
\hline RET & 287 & 0,7593 & 1,5791 & $-0,8938$ & 15,1210 & 142 & 0,1204 & 0,6649 & $-0,6874$ & 5,1180 \\
\hline
\end{tabular}

Definição das variáveis: $B T D$ é a diferença entre o LAIR e o LT escalonada pelo valor da ação defasado; BTDTE é a BTD temporária; BTDTP é a BTD permanente; LAIR é o lucro contábil antes do imposto de renda escalonado pelo valor da ação defasado; $L T$ é o lucro tributável escalonado pelo valor da ação defasado; $R E T$ corresponde ao retorno da ação escalonado pelo valor da ação defasado.

Fonte: elaborada pelos autores

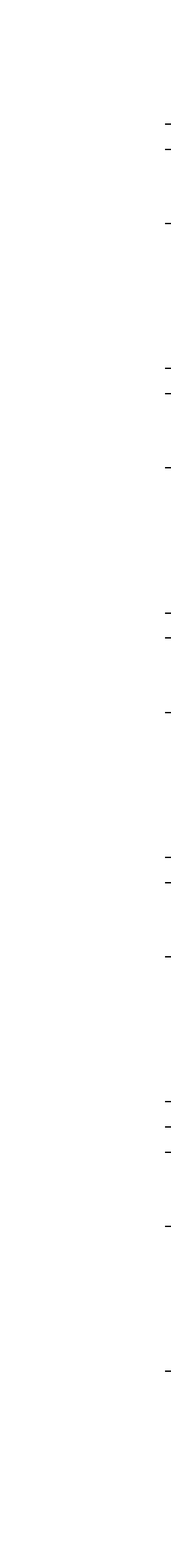


Os dados foram segregados em dois períodos: pré e pós-adoção das IFRS. Identificase que, para Argentina, Brasil e México, as médias indicadas para BTD seguem comportamento similar em relação aos sinais encontrados para a América Latina em seu todo. Os valores médios dos resultados tributáveis, nesses países, superam os financeiros, indicando, então, a correspondência com o sinal negativo identificado nos valores encontrados para a variável BTD. Ao observar os valores para a BTD na Argentina, em período pré e pós IFRS, tem-se a alteração nos sinais. Entretanto, estatisticamente, as médias continuam iguais entre os períodos

Para o Chile e Peru, são identificadas médias positivas para a BTD, com média de resultados financeiros superiores às médias para os resultados tributáveis. A condição entre as médias de LAIR e LT para Chile e Peru é confirmada por meio do teste de médias, que demonstra maior valor para média referente ao resultado financeiro (LAIR). Para o México, tanto no período pré-adoção das IFRS como no período pós-adoção, as médias para $B T D$, $B T D T E$ e BTDTP apresentam sinais negativos, o que pode sugerir maior volume em resultados tributários que financeiros. Mesmo que as médias das variáveis LAIR e LT estejam, estatisticamente, iguais no período pré e pós-adoção, em valores absolutos, o resultado tributável supera o financeiro.

Os dados relacionados às companhias abertas, listadas no Peru, demonstram alteração nas Os dados relacionados às companhias abertas, listadas no Peru, demonstram alteração nas médias das diferenças entre o período pré e pós-adoção. Na Tabela 3, para o período pósadoção, houve redução na média da $B T D, B T D T E$ e BTDTP. Conjuntamente, em valores absolutos, para a diferença entre as médias da variável LT e LAIR, se mantiveram com o LAIR mais elevado que o LT, possivelmente, justificando as modificações das médias entre os períodos pré e pós-adoção.

\subsection{Resultados para Conservadorismo Contábil}

$\mathrm{Na}$ Tabela 4, são relacionados os resultados da Equação 5, seguindo o propósito de verificar a existência do conservadorismo condicional e incondicional nos países que fazem parte da amostra desta pesquisa, bem como da América Latina.

A fórmula foi aplicada com base em duas variáveis diferentes como dependentes: o resultado tributável (LT) e o resultado financeiro (LAIR). A dupla aplicação se deve à possibilidade de ser encontrado comportamento diferente entre elas e o conservadorismo contábil. Pela concepção de Heltzer (2009), no LT é mais provável a existência do conservadorismo incondicional do que no LAIR. Por outro lado, o conservadorismo condicional pode estar mais relacionado com o LAIR que com o LT (HELTZER, 2009). Estima-se que o conservadorismo condicional não possa ser identificado de maneira expressiva no LT, já que essas informações não são comumente usadas para tomadas de decisão (NAKAO, 2012).

Por meio da metodologia empregada por Heltzer (2009), é possível identificar o conservadorismo condicional e incondicional ao se aplicar a fórmula desenvolvida por Basu (1997). O conservadorismo condicional é observado por meio da variável DRET_RET $\left(\alpha_{3}\right)$, e o conservadorismo incondicional é obtido pela soma do intercepto $\left(\alpha_{0}\right)$ com a variável DRET $\left(\alpha_{1}\right)$. Espera-se que, na presença do conservadorismo, os valores encontrados sejam positivos. 
Cassius Klay Silva Santos, Patrícia de Souza Costa, Pablo Rogers Silva

Tabela 4 - Resultados estimados para Conservadorismo Contábil

\begin{tabular}{|c|c|c|c|c|c|c|c|c|c|c|}
\hline & \multirow{3}{*}{ Variáveis } & \multirow{3}{*}{$\begin{array}{c}\text { Sinal } \\
\text { Previsto }\end{array}$} & \multicolumn{4}{|c|}{ América Latina } & \multicolumn{4}{|c|}{ Argentina } \\
\hline & & & \multicolumn{2}{|l|}{$L T$} & \multicolumn{2}{|c|}{ LAIR } & \multicolumn{2}{|c|}{$L T$} & \multicolumn{2}{|c|}{ LAIR } \\
\hline & & & Coef. & $t$ & Coef. & $t$ & Coef. & $t$ & Coef. & $t$ \\
\hline$\alpha 1$ & DRET & $?$ & $-0,067 * * *$ & $-4,25$ & $-0,088 * * *$ & $-4,25$ & $-0,053$ & $-0,8$ & $-0,171 * *$ & $-2,22$ \\
\hline$\alpha 2$ & $R E T$ & $?$ & $0,092 * * *$ & 8,43 & $0,133 * * *$ & 8,43 & $0,202 * *$ & 2,16 & $0,269 * * *$ & 3,12 \\
\hline$\alpha 3$ & $D R E T \_R E T$ & + & $-0,097 * * *$ & $-3,5$ & $-0,070 * * *$ & $-3,5$ & $-0,15$ & $-1,11$ & $-0,28$ & $-1,29$ \\
\hline \multirow[t]{2}{*}{$\alpha 0$} & Intercepto & $?$ & $0,162 * * *$ & 19,68 & $0,189 * * *$ & 19,68 & $0,243 * * *$ & 3,68 & $0,229 * * *$ & 3,63 \\
\hline & $\begin{array}{l}\mathrm{n} \text { (obs.) } \\
\mathrm{R}^{2} \text { ajustado } \\
\text { F ou Wald } \\
\text { Modelo }\end{array}$ & & \multicolumn{2}{|c|}{$\begin{array}{c}4208 \\
0,077 \\
61,671 * * * \\
\text { Fixed Effects }\end{array}$} & \multicolumn{2}{|c|}{$\begin{array}{c}4198 \\
0,094 \\
76,759^{* * *} \\
\text { Fixed Effects } \\
\end{array}$} & \multicolumn{2}{|c|}{$\begin{array}{c}428 \\
0,033 \\
20,222 * * * \\
\text { Random Effects }\end{array}$} & \multicolumn{2}{|c|}{$\begin{array}{c}429 \\
0,088 \\
30,822 * * * \\
\text { Random Effects } \\
\end{array}$} \\
\hline & \multirow{3}{*}{ Variáveis } & \multirow{3}{*}{$\begin{array}{c}\text { Sinal } \\
\text { Previsto }\end{array}$} & \multicolumn{4}{|c|}{ Brasil } & \multicolumn{4}{|c|}{ Chile } \\
\hline & & & \multicolumn{2}{|l|}{$\boldsymbol{L T}$} & \multicolumn{2}{|c|}{ LAIR } & \multicolumn{2}{|c|}{$L T$} & \multicolumn{2}{|c|}{ LAIR } \\
\hline & & & Coef. & $t$ & Coef. & $t$ & Coef. & $t$ & Coef. & $t$ \\
\hline$\alpha 1$ & DRET & $?$ & $-0,083 * * *$ & $-3,57$ & $-0,151 * * *$ & $-3,87$ & $-0,029 *$ & $-1,77$ & $-0,012$ & $-0,680$ \\
\hline$\alpha 2$ & $R E T$ & $?$ & $0,073 * * *$ & 5,58 & $0,101 * * *$ & 5,98 & $0,031 * * *$ & 2,94 & $0,079 * * *$ & 3,970 \\
\hline$\alpha 3$ & DRET_RET & + & $-0,109 * * *$ & $-3,2$ & $-0,105$ & $-1,64$ & 0,034 & 0,72 & 0,027 & 0,440 \\
\hline \multirow[t]{5}{*}{$\alpha 0$} & Intercepto & $?$ & $0,168 * * *$ & 13,2 & $0,225 * * *$ & 12,38 & $0,112 * * *$ & 13,81 & $0,114 * * *$ & 11,070 \\
\hline & $\begin{array}{l}\mathrm{n}(\text { obs.) } \\
\mathrm{R}^{2} \text { ajustado } \\
\text { F ou Wald } \\
\text { Modelo }\end{array}$ & & $\begin{array}{r}1903 \\
0,076 \\
27,417^{*} \\
\text { Fixed Efj } \\
\end{array}$ & $\begin{array}{l}* * \\
\text { ects }\end{array}$ & $\begin{array}{r}189 \\
0,0 \\
34,97 \\
\text { Fixed } E \\
\end{array}$ & $\begin{array}{l}* * \\
\text { ects }\end{array}$ & $\begin{array}{r}746 \\
0,06 \\
15,269 \\
\text { Fixed E } \\
\end{array}$ & $\begin{array}{l}* * \\
\text { ects }\end{array}$ & $\begin{array}{r}75 \\
0,08 \\
17,343 \\
\text { Fixed E } \\
\end{array}$ & $\begin{array}{l}0 \\
* * * \\
\text { ffects }\end{array}$ \\
\hline & \multirow{3}{*}{ Variáveis } & \multirow{3}{*}{$\begin{array}{c}\text { Sinal } \\
\text { Previsto }\end{array}$} & \multicolumn{4}{|c|}{ México } & \multicolumn{4}{|c|}{ Peru } \\
\hline & & & \multicolumn{2}{|l|}{$L T$} & \multicolumn{2}{|c|}{ LAIR } & \multicolumn{2}{|l|}{$L T$} & \multicolumn{2}{|c|}{ LAIR } \\
\hline & & & Coef. & $t$ & Coef. & $t$ & Coef. & $t$ & Coef. & $t$ \\
\hline$\alpha 1$ & DRET & $?$ & $-0,063 * *$ & $-2,07$ & $-0,031$ & $-1,280$ & $-0,045$ & $-0,99$ & $-0,019$ & $-0,360$ \\
\hline$\alpha 2$ & RET & $?$ & $0,115 * * *$ & 4,32 & $0,178 * * *$ & 6,290 & $0,222 * * *$ & 4,74 & $0,260 * * *$ & 5,930 \\
\hline$\alpha 3$ & $D R E T \_R E T$ & + & $-0,122 * *$ & $-2,07$ & $-0,101$ & $-1,390$ & $-0,118$ & $-1,39$ & $-0,091$ & $-0,980$ \\
\hline$\alpha 0$ & Intercepto & $?$ & $0,123 * * *$ & 7,82 & $0,106 * * *$ & 7,550 & $0,228 * * *$ & 5,77 & $0,255 * * *$ & 5,060 \\
\hline & $\begin{array}{l}\mathrm{n} \text { (obs.) } \\
\mathrm{R}^{2} \text { ajustado } \\
\text { F ou Wald } \\
\text { Modelo }\end{array}$ & & $\begin{array}{r}695 \\
0,068 \\
19,627^{*} \\
\text { Fixed Ef }\end{array}$ & $\begin{array}{l}* * \\
e c t s\end{array}$ & $\begin{array}{r}68 \\
0,1 \\
28,27 \\
\text { Fixed } E\end{array}$ & ** & $\begin{array}{r}410 \\
0,21 \\
51,666 \\
\text { Random } \\
\end{array}$ & ** & $\begin{array}{r}412 \\
0,20 \\
60,535 \\
\text { Random }\end{array}$ & $\begin{array}{l}7 \\
* * * \\
\text { Effects }\end{array}$ \\
\hline
\end{tabular}

Definição das variáveis: RET é o retorno da ação acumulado em 12 meses do período $t$-1 para o período $t$, defasado pelo valor em $t-1$; DRET é a dummy para retorno das ações, assumindo valor igual a 1 , quando $R E T$ é negativo e valor igual a 0 para as demais situações; LAIR é o lucro contábil antes do imposto de renda escalonado pelo valor da ação defasado; $L T$ é o lucro tributável escalonado pelo valor da ação defasado. Sendo * $\mathrm{p}<10 \% ; * * \mathrm{p}<5 \% ; * * * \mathrm{p}<1 \%$.

Fonte: elaborada pelos autores

Ao tomar o LT como variável dependente, os resultados estimados para conservadorismo condicional $\left(\alpha_{3}\right)$ foram significativos para o Brasil $(-0,109)$ e México ($0,122)$, nos níveis de $1 \%$ e $5 \%$, respectivamente. $O$ sinal negativo sugere que o conservadorismo contábil não está presente nas informações das companhias listadas na bolsa de valores desses países, em função do resultado tributável. Para as demais amostras, não houve resultados significativos para $\alpha_{3}$ em relação ao LT.

Quanto ao conservadorismo incondicional $\left(\alpha_{0}+\alpha_{1}\right)$, em função da variável $L T$, os resultados foram significativos para ambas as variáveis nas amostras relativas ao Brasil $(0,168)$ e $(-0,083)$, Chile $(0,112)$ e $(-0,029)$ e México $(0,123)$ e $(-0,063)$. Os resultados para o cálculo para as amostras referentes ao Brasil, Chile e México são, respectivamente, 0,085; 
0,083 e 0,060 . Os resultados com sinal positivo fazem com que se espere a presença de conservadorismo incondicional para as amostras observadas, em relação ao LT. Esses resultados corroboram aqueles encontrados por Heltzer (2009).

Os resultados estimados para a América Latina utilizando a variável LT como dependente foram todos significativos no nível de 1\%. Em relação ao conservadorismo condicional $\left(\alpha_{3}\right)$, estimou-se, para a América Latina (-0,097), o sinal negativo, contrário ao esperado, o que sugere que as companhias latino-americanas não evidenciam conservadorismo condicional nas informações contábeis na presença do resultado tributável. Em relação ao conservadorismo incondicional $\left(\alpha_{0}+\alpha_{1}\right)$, estimou-se um valor de 0,095 , indicando a presença do conservadorismo incondicional.

Na Tabela 4, também são apresentados os resultados estimados em função do lucro contábil (LAIR). Para o conservadorismo condicional ( $\alpha 3)$, as amostras relativas aos países não apresentaram nenhuma significância estatística; desta forma, aos países, individualmente, não é possível inferir essa forma de conservadorismo. Para o conservadorismo incondicional $(\alpha 0+\alpha 1)$, houve resultados significativos para Argentina $(0,229)$ e $(-0,171)$ e Brasil $(0,225)$ e $(-0,151)$. A soma dos coeficientes resultou nos seguintes valores: 0,058 e 0,074 para Argentina e Brasil, respectivamente. Os valores positivos sugerem a presença do conservadorismo incondicional nos relatórios emitidos pelas companhias listadas nesses países.

Para a América Latina, os resultados foram significantes em relação ao conservadorismo condicional. $O$ valor negativo de $-0,070$, pela orientação de Heltzer (2009), sugere que não há conservadorismo condicional na presença do LAIR. Já em relação ao conservadorismo incondicional $(\alpha 0+\alpha 1)$, o resultado estimado de 0,099 sugere que, pelas informações divulgadas pelas companhias latino-americanas, ele existe.

Os resultados da pesquisa indicam a presença de conservadorismo incondicional tanto no lucro tributável quanto no LAIR, sugerindo que as informações contábeis dos países da América Latina podem não estar relacionadas à maior qualidade. Esses resultados corroboram aqueles encontrados por Heltzer (2009).

\subsection{Resultados para Conservadorismo e BTD Total}

Para identificar a relação entre conservadorismo e a BTD total, foi utilizado o modelo especificado na Equação 7. Na Tabela 5, são registrados os resultados estimados para os modelos em painel adequado, com o intuito de verificar a relação entre BTD e conservadorismo contábil.

Com base na metodologia aplicada por Hetlzer (2009), a relação entre conservadorismo incondicional e BTD pode ser apurada por meio da variável BTD $\left(\alpha_{4}\right)$, considerando que o sinal positivo $\left(\alpha_{4}>0\right)$ e significante representa menor possibilidade de conservadorismo incondicional. Com a finalidade de identificar a relação entre BTD e conservadorismo condicional, é observado o sinal existente na variável BTD_DRET_RET $\left(\alpha_{7}\right)$, assim, quando obtido sinal positivo $\left(\alpha_{7}>0\right)$, entende-se haver maior representatividade do conservadorismo condicional, na presença da BTD.

Ao realizar a análise individual dos países tendo como variável dependente o resultado tributável (LT), observa-se que as amostras relativas à Argentina $(-0,452)$ e ao México ($0,560)$ apresentaram resultado negativo $\left(\alpha_{4}<0\right)$ quanto ao conservadorismo incondicional, com significância em nível de 5\% e 1\%. O sinal negativo sugere que, na presença da BTD, o 
resultado tributável tem elevação do conservadorismo incondicional nas informações reportadas pelas companhias listadas nas bolsas de valores nesses países. Desta forma, a hipótese $\mathrm{H}_{2}$ foi rejeitada para Argentina e México ao se avaliar o LT. Para os demais países os resultados não apresentaram significância estatística.

Espera-se aumento do conservadorismo condicional ao se observar a interação deste com a BTD, ou seja, que o coeficiente $\alpha_{7}$ seja positivo $\left(\alpha_{7}>0\right)$. Tendo a variável LT como dependente os resultados foram significativos para as companhias listadas na bolsa de valores da Argentina $(1,295)$; para as demais amostras de países não houve significância, portanto, não foi possível avaliar a relação entre BTD e conservadorismo condicional. Para as companhias argentinas, a hipótese $\mathrm{H}_{1}$ não foi rejeitada, pois as companhias revelaram elevação do conservadorismo condicional em relação à BTD, em função do LT.

Para a América Latina, ao utilizar o LT como variável dependente, houve resultados significativos para o conservadorismo incondicional $\left(\alpha_{7}\right)$ e condicional $\left(\alpha_{4}\right)$, conforme apresentado também na Tabela 5. O resultado identificado fez com que as hipótese $\mathrm{H}_{1}$ e $\mathrm{H}_{2}$ fossem rejeitadas, pois o fato de $\alpha_{7}(-0,159)$ ter sinal negativo sugere a redução do conservadorismo condicional para as companhias da América Latina, sendo contrário ao esperado na presença da BTD. O resultado negativo para $\alpha_{4}(-0,267)$ implica a expectativa de elevação do conservadorismo incondicional na presença da BTD em relação ao LT.

Tabela 5 - Interação entre BTD e Conservadorismo Contábil

\begin{tabular}{|c|c|c|c|c|c|c|c|c|c|}
\hline \multirow{3}{*}{ Variáveis } & \multirow{3}{*}{$\begin{array}{c}\text { Sinal } \\
\text { Previsto }\end{array}$} & \multicolumn{4}{|c|}{ América Latina } & \multicolumn{4}{|c|}{ Argentina } \\
\hline & & \multicolumn{2}{|l|}{$L T$} & \multicolumn{2}{|c|}{ LAIR } & \multicolumn{2}{|l|}{$L T$} & \multicolumn{2}{|c|}{ LAIR } \\
\hline & & Coef. & $t$ & Coef. & $t$ & Coef. & $Z$ & Coef. & $z$ \\
\hline DRET & $?$ & $-0,065 * * *$ & $-3,920$ & $-0,065 * * *$ & $-3,920$ & $-0,036$ & $-0,480$ & $-0,036$ & $-0,480$ \\
\hline$R E T$ & $?$ & $0,109 * * *$ & 8,610 & $0,109 * * *$ & 8,610 & $0,327 * * *$ & 2,820 & $0,327 * * *$ & 2,820 \\
\hline DRET_RET & + & $-0,089 * * *$ & $-3,070$ & $-0,089 * * *$ & $-3,070$ & $-0,138$ & $-0,930$ & $-0,138$ & $-0,930$ \\
\hline$B T D^{-}$ & + & $-0,159 * * *$ & $-2,740$ & $0,841 * * *$ & 14,530 & $-0,576^{* *}$ & $-2,200$ & 0,424 & 1,620 \\
\hline BTD_DRET & $?$ & $-0,056$ & $-0,760$ & $-0,056$ & $-0,760$ & $0,735 * * *$ & 2,640 & $0,735 * * *$ & 2,640 \\
\hline$\alpha_{6} \quad B T D \_R E T$ & $?$ & 0,014 & 0,550 & 0,014 & 0,550 & $-0,227$ & $-0,380$ & $-0,227$ & $-0,380$ \\
\hline BTD_DRET_RET & + & $-0,267 * *$ & $-2,330$ & $-0,267 * *$ & $-2,330$ & $1,295 * *$ & 2,090 & $1,295 * *$ & 2,090 \\
\hline$\alpha_{0} \quad$ Intercepto & $?$ & $0,170 * * *$ & 19,570 & $0,170 * * *$ & 19,570 & $0,260 * * *$ & 2,920 & $0,260 * * *$ & 2,920 \\
\hline $\begin{array}{c}\mathrm{n}(\text { obs. }) \\
\mathrm{R}^{2} \text { ajustado } \\
\text { F ou Wald } \\
\text { Modelo }\end{array}$ & & $\begin{array}{r}4199 \\
0,094 \\
27,356^{*} \\
\text { Fixed Eff }\end{array}$ & ** & $\begin{array}{r}4199 \\
0,44 \\
208,938 \\
\text { Fixed Ef }\end{array}$ & $\begin{array}{l}* * * \\
e c t s\end{array}$ & $\begin{array}{r}427 \\
0,07 \\
55,555 \\
\text { Random } \\
\end{array}$ & ffects & $\begin{array}{r}427 \\
0,13 \\
737,82 \\
\text { Random }\end{array}$ & $\begin{array}{l}5 \\
3 * * * \\
\text { Effects }\end{array}$ \\
\hline \multirow{3}{*}{ Variáveis } & \multirow{3}{*}{$\begin{array}{c}\text { Sinal } \\
\text { Previsto }\end{array}$} & \multicolumn{4}{|c|}{ Brasil } & \multicolumn{4}{|c|}{ Chile } \\
\hline & & \multicolumn{2}{|l|}{$L T$} & \multicolumn{2}{|c|}{ LAIR } & \multicolumn{2}{|l|}{$L T$} & \multicolumn{2}{|c|}{ LAIR } \\
\hline & & Coef. & $t$ & Coef. & $t$ & Coef. & $t$ & Coef. & $t$ \\
\hline$\alpha_{1} \quad$ DRET & $?$ & $-0,093 * * *$ & $-3,770$ & $-0,093 * * *$ & $-3,770$ & -0.011 & -0.760 & -0.011 & -0.760 \\
\hline$R E T$ & $?$ & $0,084 * * *$ & 6,080 & $0,084 * * *$ & 6,080 & $0.045 * * *$ & 2.720 & $0.045 * * *$ & 2.720 \\
\hline$\alpha_{3} \quad$ DRET_RET & + & $-0,135 * * *$ & $-3,630$ & $-0,135 * * *$ & $-3,630$ & 0.054 & 1.230 & 0.054 & 1.230 \\
\hline$\alpha_{4} B T D$ & + & 0,029 & 0,840 & $1,029 * * *$ & 29,730 & -0.172 & -1.290 & $0.828 * * *$ & 6.200 \\
\hline BTD_DRET & $?$ & $-0,156$ & $-1,340$ & $-0,156$ & $-1,340$ & -0.128 & -0.510 & -0.128 & -0.510 \\
\hline$\alpha_{6} \quad B T D_{-}^{-} R E T$ & $?$ & $-0,005$ & $-0,410$ & $-0,005$ & $-0,410$ & 0.098 & 0.610 & 0.098 & 0.610 \\
\hline$\alpha_{7}$ BTD_DRET_RET & + & $-0,233$ & $-1,530$ & $-0,233$ & $-1,530$ & -0.391 & -0.600 & -0.391 & -0.600 \\
\hline$\alpha_{0} \quad$ Intercepto & $?$ & $0,174 * * *$ & 13,250 & $0,174 * * *$ & 13,250 & $0.110 * * *$ & 14.220 & $0.110 * * *$ & 14.220 \\
\hline $\begin{array}{c}\mathrm{n} \text { (obs.) } \\
\mathrm{R}^{2} \text { ajustado } \\
\text { F ou Wald } \\
\text { Modelo }\end{array}$ & & $\begin{array}{r}1899 \\
0.082 \\
13,909^{*} \\
\text { Fixed Eff }\end{array}$ & $\begin{array}{l}* * \\
e c t s\end{array}$ & $\begin{array}{r}1899 \\
0,75 \\
635,676 \\
\text { Fixed Ef }\end{array}$ & $\begin{array}{l}* * \\
\text { ects }\end{array}$ & $\begin{array}{r}739 \\
0,10 \\
10,288 \\
\text { Fixed } E\end{array}$ & fects & $\begin{array}{r}735 \\
0,61 \\
45,424 \\
\text { Fixed } E\end{array}$ & $\begin{array}{l}5 \\
* * * \\
\text { ffects }\end{array}$ \\
\hline
\end{tabular}




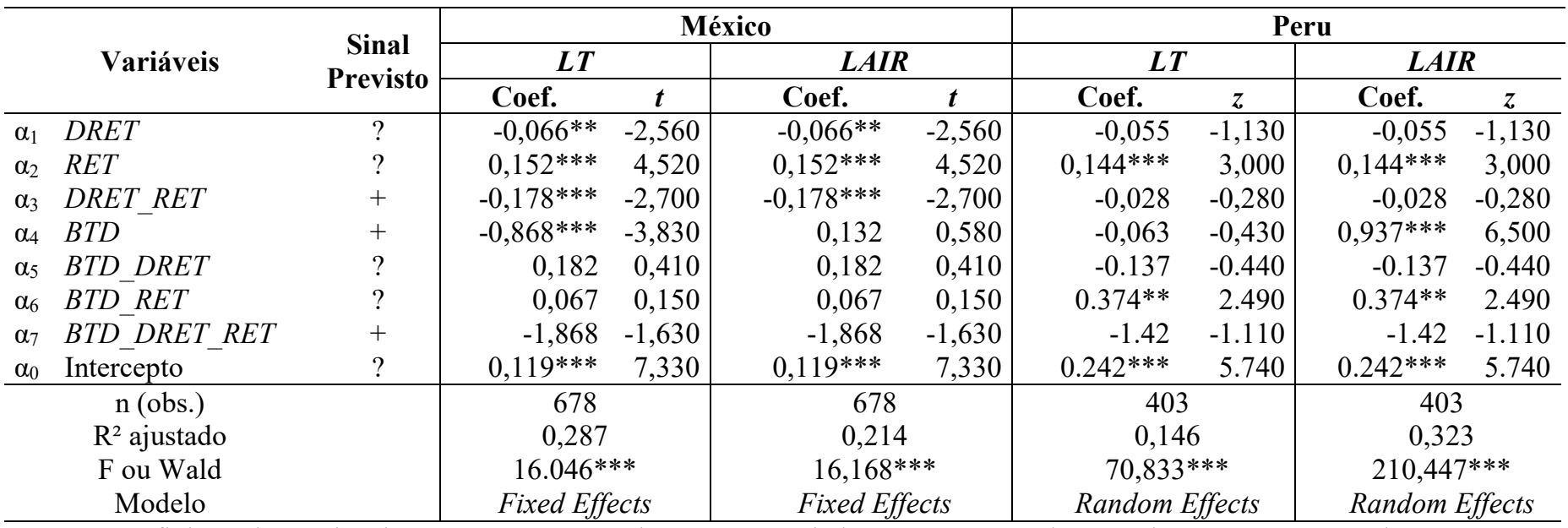

Definição das variáveis: RET é o retorno da ação acumulado em 12 meses do período $t$ - 1 para o período $t$, defasado pelo valor em $t-1$; DRET é a dummy para retorno das ações, assumindo valor igual a 1 , quando RET é negativo e o valor seja igual a 0 para as demais situações; LAIR é o lucro contábil antes do imposto de renda escalonado pelo valor da ação defasado; $L T$ é o lucro tributável escalonado pelo valor da ação defasado; $B T D$ é a diferença entre o LAIR e o LT escalonadas pelo valor por ação defasado. Sendo: $* \mathrm{p}<10 \%$; $* * \mathrm{p}<5 \%$; $* * *$ $\mathrm{p}<1 \%$.

Fonte: elaborada pelos autores

Para os resultados considerando o LAIR como variável dependente, o coeficiente $\alpha_{4}$, relacionado ao conservadorismo incondicional, apresentou significância para as companhias relativas ao Brasil $(1,029)$, Chile $(0,828)$ e Peru $(0,937)$ na interação com a BTD. Todos os países com resultados significativos revelaram sinal positivo $\left(\alpha_{7}>0\right)$, conforme esperado; desta maneira, sugere-se que o conservadorismo incondicional fica reduzido na presença da BTD, fazendo com que a hipótese $\mathrm{H}_{2}$ não seja rejeitada para o LAIR.

Quanto aos resultados para o conservadorismo condicional $\left(\alpha_{7}\right)$, a amostra de companhias listadas na bolsa de valores da Argentina $(1,295)$ foi a única a revelar significância estatística. $\mathrm{O}$ valor positivo identificado no coeficiente faz com que se tenha a expectativa de maior conservadorismo condicional nos relatórios contábeis dessas companhias, conforme era esperado para a interação com a BTD; neste caso, a hipótese $\mathrm{H}_{1}$ não é rejeitada para as companhias argentinas na presença do LAIR.

A aplicação da Equação 7, utilizando-se a variável LAIR como dependente, estimou resultados estatisticamente significativos para a América Latina. Para o conservadorismo incondicional $\alpha_{4}$, o resultado foi de 0,841 e o valor positivo $\left(\alpha_{4}>0\right)$ sugere menor presença do conservadorismo incondicional, conforme indicado na hipótese $\mathrm{H}_{2}$. Em relação ao conservadorismo condicional, estima-se uma redução, pois, para a América Latina (-0,267), o sinal encontrado foi contrário ao esperado; desta maneira, a hipótese $\mathrm{H}_{1}$ é rejeitada para as companhias em função do LAIR.

Os resultados sugerem redução do conservadorismo condicional (tanto no LT quanto no LAIR), na presença de maior BTD total, nos países da América Latina. Esse resultado é contrário ao esperado, podendo sugerir menor qualidade da informação reportada. Por outro lado, foi identificado um aumento do conservadorismo incondicional no lucro tributável e redução no lucro contábil, sugerindo maior gerenciamento no lucro tributável. Esse resultado é similar ao encontrado por Heltzer (2009). 


\subsection{Resultados para Conservadorismo, BTDTE e BTDTP}

A Equação 8 é aplicada com a finalidade de identificar a relação existente entre conservadorismo contábil e a BTDTP e BTDTE. Os resultados estimados para os modelos em painel adequado são descritos na Tabela 6 .

Os resultados são baseados nas variáveis $\operatorname{BTDTP}\left(\alpha_{4}\right)$ e BTDTE $\left(\alpha_{5}\right)$, para observar o nível de conservadorismo incondicional, e nas variáveis BTDTP_DRET_RET $\left(\alpha_{10}\right)$ e BTDTE _DRET_RET $\left(\alpha_{11}\right)$ para o conservadorismo condicional. Caso os resultados para $\alpha_{4}$ tenham sinal positivo $\left(\alpha_{4}>0\right)$, estima-se que, na presença da BTDTP, ocorra menor existência de conservadorismo incondicional nas informações. A avaliação para a BTDTE quanto ao conservadorismo incondicional é baseada no fato de que se $\alpha 5$ tiver sinal negativo, espera-se maior relação entre o conservadorismo incondicional e a BTDTE.

Para identificar o conservadorismo condicional, tem-se como parâmetro que resultados com sinal positivo $\left(\alpha_{10}>0\right)$ sugerem maior presença de conservadorismo condicional em amostras com BTDTP. Para as amostras relativas ao BTDTE, se o coeficiente $\alpha_{11}$ for negativo $\left(\alpha_{11}<0\right)$, supõe-se que haja menor relação entre o conservadorismo condicional e a BTDTE.

Os resultados descritos na Tabela 6 revelam que, ao tomar-se o resultado tributário (LT) como variável dependente, Argentina $(-0,505)$ e México $(-1,232)$ são os únicos a apresentar significância estatística, quando avaliada a $\operatorname{BTDTP}\left(\alpha_{4}\right)$. O sinal negativo $\left(\alpha_{4}<0\right)$ sugere que, nesta situação, as informações tenham maior relação com o conservadorismo incondicional, pelas amostras desses países. Pelo fato dos demais países não apresentarem significância em seus resultados para a variável em questão $\left(\alpha_{4}\right)$, não é possível inferir comportamento para eles em relação ao conservadorismo incondicional e BTDTP em função da variável LT.

Na relação entre BTDTP $\left(\alpha_{10}\right)$ e conservadorismo condicional, tendo como variável dependente o LT, têm-se resultados significativos para Argentina $(-3,120)$ e Peru $(-2,457)$. Os resultados com sinal negativo $\left(\alpha_{10}<0\right)$ para Argentina e Peru sugerem que as informações reportadas pelas companhias abertas listadas nesses países estejam com menor presença de conservadorismo condicional, o que é contrário ao esperado em amostras com BTDTP.

Observando o resultado exposto na Tabela 6 para BTDTE, considerando-se a variável LT como dependente, são identificados para o Chile $(303,43)$ e Peru $(33,343)$ valores com significância de $1 \%$ e $10 \%$. Os resultados com sinal positivo $\left(\alpha_{5}>0\right)$ são contrários ao esperado, sugerindo que, nessas amostras, o conservadorismo incondicional se torna menos presente, contrariando a hipótese $\mathrm{H}_{3}$ em função do LT. Para o conservadorismo condicional $\left(\alpha_{11}\right)$, houve resultados significativos apenas para o México $(-1,884)$, no nível de $5 \%$. $O$ resultado negativo $\left(\alpha_{11}<0\right)$ era esperado para amostras com presença de BTDTE. Supõe-se que as companhias mexicanas nessa situação apresentem menor relação entre conservadorismo condicional e BTDTE em função do LT.

Os resultados encontrados, quando observada a amostra representando a América Latina, na condição da existência de BTDTP, com a variável LT como dependente, não foram significativos para conservadorismo incondicional $\left(\alpha_{4}\right)$ nem para conservadorismo condicional $\left(\alpha_{10}\right)$. Portanto, não é possível inferir a relação existente entre elas, o que não permite aceitar as hipóteses $\mathrm{H}_{5}$ e $\mathrm{H}_{6}$. 
Tabela 6 - Interação entre BTDTE, BTDTP e Conservadorismo Contábil

\begin{tabular}{|c|c|c|c|c|c|c|c|c|c|c|}
\hline \multirow{3}{*}{\multicolumn{2}{|c|}{ Variáveis }} & \multirow{4}{*}{$\begin{array}{c}\begin{array}{c}\text { Sinal } \\
\text { Previs to }\end{array} \\
?\end{array}$} & \multicolumn{4}{|c|}{ América Latina } & \multicolumn{4}{|c|}{ Argentina } \\
\hline & & & \multicolumn{2}{|c|}{$L T$} & \multicolumn{2}{|c|}{ LAIR } & \multicolumn{2}{|l|}{$L T$} & \multicolumn{2}{|c|}{ LAIR } \\
\hline & & & \multirow{2}{*}{$\frac{\text { Coef. }}{-0,044 * * *}$} & \multirow{2}{*}{$\begin{array}{l}t \\
-3,1\end{array}$} & \multirow{2}{*}{\begin{tabular}{c|} 
Coef. \\
$-0,048^{* * * *}$
\end{tabular}} & \multirow{2}{*}{\begin{tabular}{|l|}
$\boldsymbol{t}$ \\
$-3,42$
\end{tabular}} & \multirow{2}{*}{$\begin{array}{r}\text { Coef. } \\
0,066\end{array}$} & \multirow{2}{*}{$\frac{z}{1,05}$} & \multirow{2}{*}{$\begin{array}{c}\text { Coef. } \\
0,065\end{array}$} & $z$ \\
\hline$\alpha_{1}$ & DRET & & & & & & & & & 1,57 \\
\hline$\alpha_{2}$ & $R E T$ & $?$ & $0,089 * * *$ & 7,86 & $0,099 * * *$ & 8,42 & 0,034 & 0,46 & 0,075 & 1,13 \\
\hline$\alpha_{3}$ & RET_DRET & + & $-0,079 * * *$ & $-2,76$ & $-0,074 * *$ & $-2,46$ & 0,174 & 1,28 & 0,139 & 1,03 \\
\hline$\alpha_{4}$ & BTDTP & + & $-0,065$ & $-1,02$ & $0,534 * * *$ & 7,79 & $-0,505^{* *}$ & $-2,24$ & $1,033 * * *$ & 1,24 \\
\hline$\alpha_{5}$ & BTDTE & - & $0,156^{* * *}$ & 2,74 & $1,082 * * *$ & 14,46 & $-60,127$ & -1 & 113,381 & 0,54 \\
\hline$\alpha_{6}$ & BTDTP_DR & $?$ & $-0,154 * * *$ & $-2,89$ & $-0,309 * * *$ & $-2,72$ & $-0,335$ & $-0,6$ & $-0,407$ & $-0,84$ \\
\hline$\alpha_{7}$ & BTDTE_DR & $?$ & 0,11 & 1,09 & $0,205^{*}$ & 1,77 & 59,749 & 0,83 & 58,499 & $-0,77$ \\
\hline$\alpha_{8}$ & $B T D T P \_R E$ & $?$ & $-0,056^{*}$ & $-1,92$ & $-0,027$ & $-0,93$ & $-0,006$ & $-0,01$ & $-0,768$ & $-0,46$ \\
\hline$\alpha_{9}$ & BTDTE_RE & $?$ & $-0,091$ & $-1,57$ & $-0,005$ & $-0,08$ & 55,705 & 0,93 & $-140,015$ & $-0,09$ \\
\hline$\alpha_{10}$ & BTDTP_DR & + & 0,018 & 0,2 & $-0,312^{*}$ & $-1,77$ & $-3,120 * *$ & $-2,08$ & $-0,882$ & $-0,86$ \\
\hline$\alpha_{11}$ & BTDTE_DR & - & $-0,152$ & $-0,7$ & $-0,539^{*}$ & $-1,97$ & $-114,357$ & $-0,56$ & 375,365 & $-0,88$ \\
\hline$\alpha_{0}$ & Intercepto & $?$ & $0,140 * * *$ & 18,31 & $0,152 * * *$ & 19,51 & $0,148 * * *$ & 3,52 & $0,102 * * *$ & 4,44 \\
\hline & bs.) & & 378 & & 378 & & 176 & & 16 & \\
\hline & stado & & 0,1 & & 0,4 & & 0,046 & & 0,5 & \\
\hline & Wald & & 17,62 & & 120,21 & & $44,169^{* *}$ & & 51,32 & \\
\hline & delo & & Fixed $E$ & & Fixed $E$ & & Random Ef & rects & Random & ects \\
\hline & & & & & & & & & & \\
\hline & áveis & $\begin{array}{c}\text { Sinal } \\
\text { Previsto }\end{array}$ & $L 1$ & & $L A I$ & & $L T$ & & $\boldsymbol{L A I}$ & \\
\hline & & & Coef. & $t$ & Coef. & $t$ & Coef. & $t$ & Coef. & $t$ \\
\hline$\alpha_{1}$ & DRET & $?$ & $-0,109 * * *$ & $-4,08$ & $-0,109 * * *$ & $-4,08$ & $-0,012$ & $-1,09$ & $-0,012$ & $-1,09$ \\
\hline$\alpha_{2}$ & $R E T$ & $?$ & $0,073 * * *$ & 4,92 & $0,073 * * *$ & 4,92 & $0,042 * *$ & 2,56 & $0,042 * *$ & 2,56 \\
\hline$\alpha_{3}$ & RET_DRET & + & $-0,118^{* * *}$ & $-3,29$ & $-0,118 * * *$ & $-3,29$ & 0,047 & 1,16 & 0,047 & 1,16 \\
\hline$\alpha_{4}$ & BTDTP & + & 0,227 & 1,18 & $1,227 * * *$ & 6,35 & 0,079 & 0,72 & $-0,921 * * *$ & $-8,49$ \\
\hline$\alpha_{5}$ & BTDTE & - & 0,068 & 0,68 & $1,068 * * *$ & 10,6 & $303,432 * * *$ & 3,34 & $304,432 * * *$ & 3,36 \\
\hline$\alpha_{6}$ & $B T D T P \_D R$ & $?$ & $-0,16$ & $-1,04$ & $-0,16$ & $-1,04$ & 0,264 & 1,19 & 0,264 & 1,19 \\
\hline$\alpha_{7}$ & BTDTE_DR & $?$ & $-0,303$ & $-1,52$ & $-0,303$ & $-1,52$ & 68,896 & 0,49 & 68,896 & 0,49 \\
\hline$\alpha_{8}$ & BTDTP_RE & $?$ & $-0,021$ & $-0,75$ & $-0,021$ & $-0,75$ & $-0,014$ & $-0,11$ & $-0,014$ & $-0,11$ \\
\hline$\alpha_{9}$ & BTDTE_RE & $?$ & $-0,213 * *$ & $-2,21$ & $-0,213 * *$ & $-2,21$ & 61,953 & 0,38 & 61,953 & 0,38 \\
\hline$\alpha_{10}$ & BTDTP_DR & + & $-0,129$ & -1 & $-0,129$ & -1 & 0,693 & 1,17 & 0,693 & 1,17 \\
\hline$\alpha_{11}$ & BTDTE_DR & - & 0,161 & 0,8 & 0,161 & 0,8 & 435,977 & 1,37 & 435,977 & 1,37 \\
\hline$\alpha_{0}$ & Intercepto & $?$ & $0,185 * * *$ & 12,63 & $0,185 * * *$ & 12,63 & $0,110 * * *$ & 15,19 & $0,110 * * *$ & 15,19 \\
\hline & bs.) & & 188 & & 188 & & 73 & & 73 & \\
\hline & istado & & 0,0 & & 0,80 & & 0,21 & & 0,6 & \\
\hline & Wald & & 8,104 & & 2234,36 & & 13,338 & $* * *$ & 48,34 & \\
\hline & delo & & Fixed $E$ & & Fixed E & & Fixed E & fects & Fixed $E$ & \\
\hline & & & & & & & & & & \\
\hline & áveis & $\begin{array}{c}\text { Sinal } \\
\text { Previsto }\end{array}$ & $L 1$ & & $L A I$ & & $L T$ & & $\boldsymbol{L A I}$ & \\
\hline & & & Coef. & $t$ & Coef. & $t$ & Coef. & $z$ & Coef. & $z$ \\
\hline$\alpha_{1}$ & DRET & $?$ & $-0,130 * *$ & $-2,27$ & $-0,130^{* *}$ & $-2,27$ & $-0.063^{*}$ & -1.760 & $-0.063^{*}$ & -1.760 \\
\hline$\alpha_{2}$ & $R E T$ & $?$ & 0,061 & 0,99 & 0,061 & 0,99 & $0.110 * * *$ & 3.980 & $0.110^{* * *}$ & 3.980 \\
\hline$\alpha_{3}$ & RET_DRET & + & $-0,109$ & $-1,01$ & $-0,109$ & $-1,01$ & $-0.116^{* *}$ & -2.000 & $-0.116^{* *}$ & -2.000 \\
\hline$\alpha_{4}$ & BTDTP & + & $-1,232 * *$ & $-2,36$ & $-1,232 * *$ & $-2,36$ & 0.201 & 0.560 & $1.201 * * *$ & 3.310 \\
\hline$\alpha_{5}$ & BTDTE & - & $-0,773$ & $-0,9$ & $-0,773$ & $-0,9$ & $33.343 * * *$ & 3.770 & $34.343 * * *$ & 3.890 \\
\hline$\alpha_{6}$ & BTDTP_DR & $?$ & $0,889 *$ & 1,73 & $0,889 *$ & 1,73 & 0.136 & 0.360 & 0.136 & 0.360 \\
\hline$\alpha_{7}$ & BTDTE_DR & $?$ & 1,177 & 1,37 & 1,177 & 1,37 & $-39.700 * * *$ & -3.300 & $-39.700 * * *$ & -3.300 \\
\hline$\alpha_{8}$ & BTDTP_RE & $?$ & 0,081 & 0,15 & 0,081 & 0,15 & $0.445^{* * *}$ & 5.140 & $0.445^{* * *}$ & 5.140 \\
\hline$\alpha_{9}$ & BTDTE_RE & $?$ & 0,391 & 0,8 & 0,391 & 0,8 & $-34.270 * * *$ & -8.280 & $-34.270^{* * *}$ & -8.280 \\
\hline$\alpha_{10}$ & BTDTP_DR & + & $-0,846$ & $-1,07$ & $-0,846$ & $-1,07$ & $-2.457^{*}$ & -1.790 & $-2.457^{*}$ & -1.790 \\
\hline$\alpha_{11}$ & $B T D T E \_D R$ & - & $-1,884 * *$ & $-2,34$ & $-1,884 * *$ & $-2,34$ & -83.148 & -1.030 & -83.148 & -1.030 \\
\hline$\alpha_{0}$ & Intercepto & $?$ & $0,199 * * *$ & 5,05 & $0,199 * * *$ & 5,05 & $0.208 * * *$ & 5.790 & $0.208 * * *$ & 5.790 \\
\hline & bs.) & & 71 & & 71 & & 27 & & 27 & \\
\hline & istado & & 0,5 & & 0,54 & & 0,21 & & 0,3 & \\
\hline & Wald & & 96,673 & & 96,673 & & 81335,0 & $0 * * *$ & 116671, & $* * *$ \\
\hline & delo & & Fixed $E$ & & Fixed $E$ & & Random & Effects & Random & ects \\
\hline
\end{tabular}

Definição das variáveis: RET é o retorno da ação acumulado em 12 meses do período $t$-1 para o período $t$, defasado pelo valor em $t$-1, DRET é a dummy para retorno das ações, assumindo valor igual a 1, quando RET é negativo e valor igual a 0 para as demais situações; LAIR é o lucro contábil antes do imposto de renda escalonado pelo valor da ação defasado; LT é o lucro tributável escalonado pelo valor da ação defasado; BTDTE é a BTD temporária; BTDTP é a BTD permanente. Sendo: * $p<10 \%$; ** $p<5 \%$; *** $p<1 \%$,

Fonte: elaborada pelos autores 
Quanto aos resultados tendo a variável LT como dependente e identificando a existência de BTDTE, na amostra para a América Latina, foi observada significância estatística, no nível de $1 \%$, para o resultado referente ao conservadorismo incondicional $\left(\alpha_{5}\right.$ com coeficiente positivo), sendo rejeitada a hipótese $\mathrm{H}_{3}$. $\mathrm{O}$ valor encontrado para a América Latina $(0,156)$, por ser positivo $\left(\alpha_{5}>0\right)$, sugere que os resultados divulgados pelas companhias latino-americanas tenham menor relação entre o conservadorismo incondicional e a BTDTE. Para o conservadorismo condicional $\left(\alpha_{11}\right)$, os resultados não foram significativos para os países da América Latina, quando considerado o LT como variável dependente, não permitindo aceitar a hipótese $\mathrm{H}_{4}$.

Por meio da aplicação da Equação 8 também são obtidos os resultados que tenham a variável LAIR como dependente. Ao verificar o nível de conservadorismo incondicional para as companhias, considerando a presença da BTDTP $\left(\alpha_{4}\right)$, todos os países apresentaram resultados significativos. Os resultados estimados positivos, $\left(\alpha_{4}>0\right)$ para Argentina $(1,033)$, Brasil $(1,227)$ e Peru $(1,201)$, sugerem que as companhias listadas nesses países têm menor relação entre conservadorismo contábil e BTDTP, conforme esperado, em função do LAIR. Logo, a hipótese $\mathrm{H}_{6}$ não foi rejeitada. Para as companhias listadas nas bolsas chilena e mexicana, a hipótese $\mathrm{H}_{6}$ foi rejeitada, devido ao fato de as estimativas encontradas para Chile $(-0,921)$ e México $(-1,232)$ terem sinal negativo, o que indica maior relação entre BTDTP e conservadorismo incondicional para essas amostras.

Ao avaliar o conservadorismo condicional para a BTDTP $\left(\alpha_{10}\right)$, foi identificado apenas o Peru $(-2,457)$ com resultados significativos. $O$ sinal negativo $\left(\alpha_{10}<0\right)$ indica que há menor relação entre o conservadorismo condicional e a BTDTP e, sendo assim, a hipótese $\mathrm{H}_{5}$ foi rejeitada para a amostra de companhias peruanas na presença do LAIR.

Espera-se que os resultados estimados pela Equação 8 informem sobre a relação entre BTPTE e conservadorismo contábil. As variáveis de interesse são referentes ao conservadorismo incondicional $\left(\alpha_{5}\right)$ e condicional $\left(\alpha_{11}\right)$. Tendo o LAIR como dependente, os resultados obtidos em relação ao conservadorismo incondicional $\left(\alpha_{5}\right)$ foram significativos para Brasil $(1,068)$, Chile $(304,43)$ e Peru $(34,34)$, todos no nível de $1 \%$. Os valores positivos $\left(\alpha_{5}>0\right)$ são contrários ao sinal que se esperava. A expectativa é que as companhias abertas, nesses países, tenham menor presença do conservadorismo incondicional na existência da BTDTE em suas informações. Desta maneira, a hipótese $\mathrm{H}_{3}$ foi rejeitada em função do LAIR.

Para os resultados referentes ao conservadorismo condicional $\left(\alpha_{11}\right)$, houve significância apenas para a amostra de empresas mexicanas, no nível de $5 \%$. O valor estimado para o México $(-1,884)$ teve sinal negativo $\left(\alpha_{11}<0\right)$, o que sugere menor presença do conservadorismo condicional nos relatórios dessas companhias na presença da BTDTE. Consequentemente, a hipótese $\mathrm{H}_{4}$ não foi rejeitada para o LAIR.

Quando se observam os dados da América Latina, é identificado que, na presença da BTDTP, para conservadorismo incondicional $\left(\alpha_{4}\right)$ e conservadorismo condicional $\left(\alpha_{10}\right)$ são significativos, ao utilizar o LAIR como variável dependente. No valor estimado de $\alpha_{4}$ para a América Latina $(0,534)$, por ser positivo, tem-se a percepção de menor existência do conservadorismo incondicional em relação a BTDTP, conforme esperado, sendo assim, a hipótese $\mathrm{H}_{6}$ não foi rejeitada em função do LAIR. Para a América Latina $\alpha_{10}(-0,312)$ é acompanhado de sinal negativo $\left(\alpha_{10}<0\right)$, fazendo com que a hipótese $\mathrm{H}_{5}$ seja rejeitada na presença do LAIR, pois sugere-se que, nesta situação, há menor relação entre o conservadorismo condicional e a BTDTP. 
Para a relação entre BTDTE e conservadorismo, tendo a variável LAIR como dependente, os resultados para $\alpha_{5}$ e $\alpha_{11}$ foram significativos no nível de $10 \%$ e $5 \%$, respectivamente. $\mathrm{O}$ conservadorismo incondicional resultante para a América Latina $(1,082)$, acompanhado de sinal positivo $\left(\alpha_{5}>0\right)$, indica que há menor relação entre a BTDTE e o conservadorismo incondicional nas informações contábeis; logo, a hipótese $\mathrm{H}_{3}$ foi rejeitada para o LAIR. O resultado estimado para a América Latina $(-0,539)$ em $\alpha_{11}$ acompanha sinal negativo $\left(\alpha_{11}<0\right)$, o que motiva a menor relação entre conservadorismo condicional e a BTDTE, fazendo com que a hipótese $\mathrm{H}_{4}$ não seja rejeitada para o LAIR.

Os resultados sugerem que a BTD temporária não está positivamente relacionada com o conservadorismo incondicional, com LAIR ou LT como variáveis independentes. Porém, a BTDTE está relacionada negativamente com o conservadorismo condicional, quando o LAIR é a variável dependente, o que pode sugerir menor qualidade das informações financeiras. $\mathrm{Na}$ mesma linha de pensamento, a BTD permanente não está positivamente relacionada com o conservadorismo condicional, com LAIR ou LT como variáveis independentes. Porém a BTDP está relacionada positivamente com o conservadorismo incondicional quando o LAIR é a variável dependente, o que pode sugerir também menor qualidade das informações financeiras.

\subsection{Resultados para Conservadorismo, LPBTD e LNBTD}

Os resultados obtidos com a aplicação da Equação 6 são apresentados na Tabela 7. Esses testes têm o objetivo de avaliar a relação entre conservadorismo e as book-tax differences por outra perspectiva: large positive $\mathrm{BTD}$ (LPBTD) e large negative $\mathrm{BTD}$ (LNBTD), que são as extremidades para os dados em BTD positiva (BTDPO) e BTD negativa (BTDNE).

Por meio dos resultados obtidos com a Equação 6, são identificadas as relações existentes entre as LPBTD e $L N B T D$ com o conservadorismo contábil. As variáveis de interesse para essa proposta são a LPBTD $\left(\alpha_{4}\right)$ e $\operatorname{LNBTD}\left(\alpha_{5}\right)$ relacionadas ao conservadorismo incondicional, e as variáveis LPBTD_DRET_RET $\left(\alpha_{10}\right)$ e LNBTD_DRET_RET $\left(\alpha_{11}\right)$ para o conservadorismo condicional. Quando forem identificados coeficientes para a variável $\alpha_{4}$, que avalia o conservadorismo incondicional em função das LPBTD com sinal negativo $\left(\alpha_{4}<0\right)$, entende-se que há maior presença do conservadorismo incondicional nas informações reportadas ao mercado. O mesmo é válido para a variável $\operatorname{LNBTD}\left(\alpha_{5}\right)$. Em relação às variáveis relativas ao conservadorismo condicional $\alpha_{10}$ para as LPBTD e $\alpha_{11}$ para as $L N B T D$, quando apresentam sinal negativo $\left(\alpha_{10}<0\right)$ e $\left(\alpha_{11}<0\right)$ entende-se haver menor presença do conservadorismo condicional nas informações contábeis. 
Tabela 7 - Interação entre $L P B T D, L N B T D$ e Conservadorismo Contábil

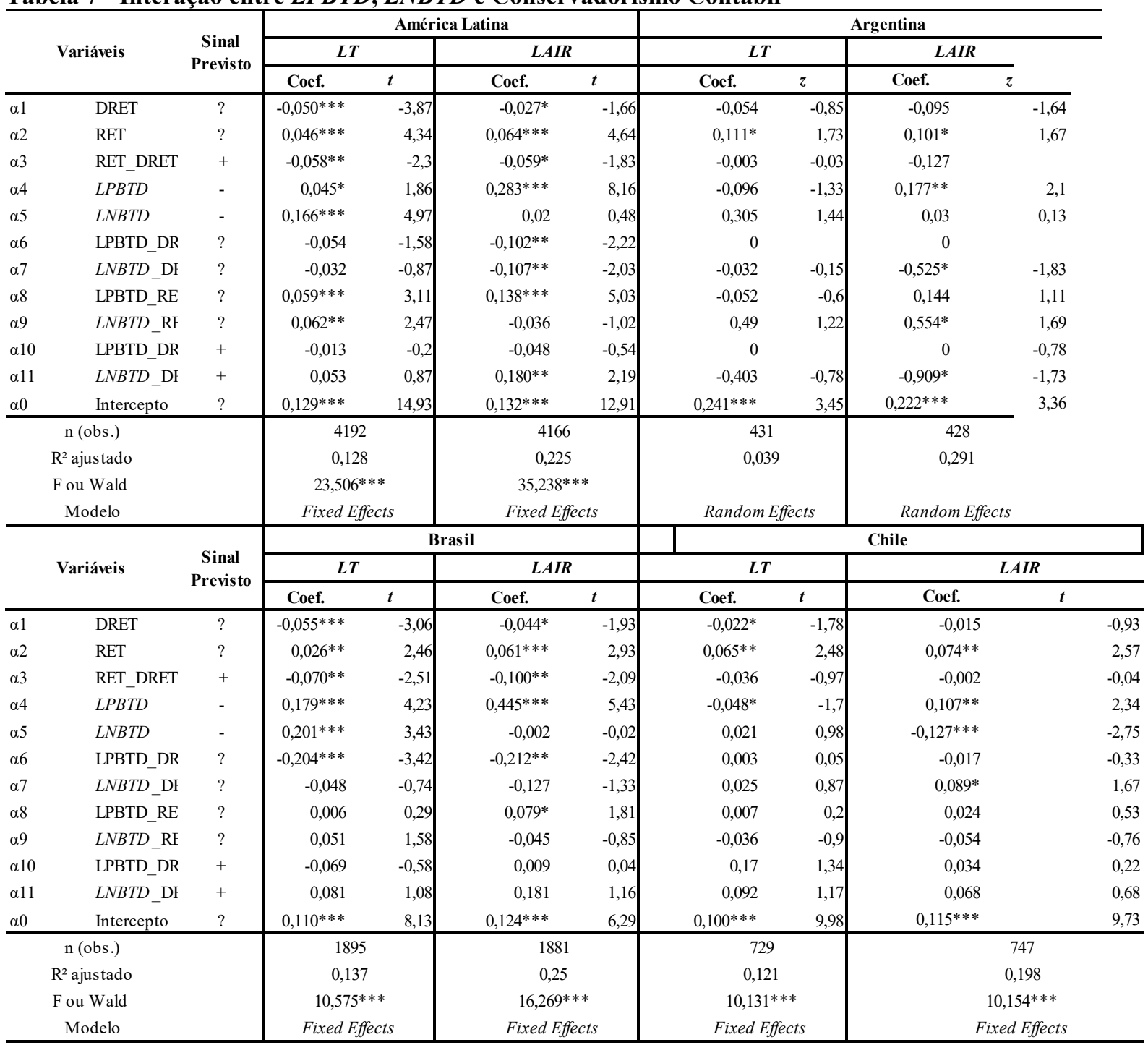


Relação entre book-tax differences e conservadorismo contábil: um estudo das companhias abertas de países da América Latina

\begin{tabular}{|c|c|c|c|c|c|c|c|c|c|c|}
\hline & \multirow{3}{*}{ Variáveis } & \multirow{3}{*}{$\begin{array}{c}\text { Sinal } \\
\text { Previs to }\end{array}$} & \multicolumn{4}{|c|}{ México } & \multicolumn{4}{|c|}{ Peru } \\
\hline & & & \multicolumn{2}{|c|}{$L T$} & \multicolumn{2}{|c|}{ LAIR } & \multicolumn{2}{|c|}{$L T$} & \multicolumn{2}{|c|}{ LAIR } \\
\hline & & & Coef. & $t$ & Coef. & $t$ & Coef. & $z$ & Coef. & $z$ \\
\hline$\alpha 1$ & DRET & $?$ & $-0,029$ & $-1,43$ & $-0,021$ & $-0,95$ & $-0,053$ & $-1,24$ & $-0,045$ & $-0,91$ \\
\hline$\alpha 2$ & RET & $?$ & $0,090 * * *$ & 3,9 & $0,098 * * *$ & 4,27 & $0,099 * * *$ & 2,71 & $0,100 * * *$ & 2,66 \\
\hline$\alpha 3$ & RET_DRET & + & $-0,094^{*}$ & $-1,86$ & $-0,068$ & $-1,13$ & $-0,073$ & $-0,88$ & $-0,021$ & $-0,23$ \\
\hline$\alpha 4$ & LPBTD & - & $-0,015$ & $-0,26$ & 0,093 & 1,29 & 0,105 & 0,82 & $0,385 * * *$ & 3,22 \\
\hline$\alpha 5$ & $L N B T D$ & - & $0,142 * *$ & 2,22 & $-0,037$ & $-0,55$ & 0,047 & 0,63 & $-0,091$ & $-0,94$ \\
\hline$\alpha 6$ & LPBTD_DR & $?$ & $-0,11$ & $-1,35$ & $-0,072$ & $-0,84$ & $-0,08$ & $-0,57$ & $-0,244^{*}$ & $-1,74$ \\
\hline$\alpha 7$ & $L N B T D \_D I$ & $?$ & $-0,003$ & $-0,04$ & $0,148 * *$ & 2,22 & 0,032 & 0,26 & 0,14 & 1,1 \\
\hline$\alpha 8$ & LPBTD_RE & $?$ & 0,076 & 1,33 & $0,210^{*}$ & 1,67 & 0,176 & 1,42 & 0,137 & 1,45 \\
\hline$\alpha 9$ & $L N B T D \_\mathrm{RF}$ & $?$ & $0,289^{*}$ & 1,95 & $0,326^{* *}$ & 2,47 & 0,04 & 0,5 & 0,072 & 0,9 \\
\hline$\alpha 10$ & LPBTD_DR & + & $-0,401^{*}$ & $-1,81$ & $-0,654 * *$ & $-2,21$ & $-0,135$ & $-0,3$ & $-1,233 * *$ & $-2,27$ \\
\hline$\alpha 11$ & LNBTD_DI & + & $-0,15$ & $-0,63$ & 0,342 & 1,29 & 0,274 & 1,19 & 0,151 & 0,61 \\
\hline$\alpha 0$ & Intercepto & $?$ & $0,077 * * *$ & 4,6 & $0,078 * * *$ & 4,58 & $0,207 * * *$ & 5,65 & $0,223 * * *$ & 6,08 \\
\hline \multicolumn{3}{|c|}{ n (obs.) } & \multicolumn{2}{|c|}{688} & \multicolumn{2}{|c|}{677} & \multicolumn{2}{|c|}{405} & \multicolumn{2}{|c|}{404} \\
\hline \multicolumn{3}{|c|}{$\mathrm{R}^{2}$ ajustado } & \multicolumn{2}{|c|}{0,205} & \multicolumn{2}{|c|}{0,261} & \multicolumn{2}{|c|}{0,138} & \multicolumn{2}{|c|}{0,247} \\
\hline \multicolumn{3}{|c|}{ F ou Wald } & \multicolumn{2}{|c|}{$9,680 * * *$} & \multicolumn{2}{|c|}{$9,577 * * *$} & \multicolumn{2}{|c|}{$70,578 * * *$} & \multicolumn{2}{|c|}{$137,196^{* * *}$} \\
\hline \multicolumn{3}{|c|}{ Modelo } & \multicolumn{2}{|c|}{ Fixed Effects } & \multicolumn{2}{|c|}{ Fixed Effects } & \multicolumn{2}{|c|}{ Random Effects } & \multicolumn{2}{|c|}{ Random Effects } \\
\hline
\end{tabular}

Definição das variáveis: RET é o retorno da ação acumulado em 12 meses do período $t$ - 1 para o período $t$, defasado pelo valor em $t-1$; $D R E T$ é a dummy para retorno das ações, assumindo valor igual a 1 , quando $R E T$ é negativo, e valor igual a 0 para as demais situações; LAIR é o lucro contábil antes do imposto de renda escalonado pelo valor da ação defasado; $L T$ é o lucro tributável escalonado pelo valor da ação defasado; LNBTD é uma variável binária com valor igual a 1 quando se tem os valores mais elevados para a BTDNE; $L P B T D$ é uma variável binária com valor igual a 1 quando se tem os valores mais elevados para B BTDPO. Sendo: ${ }^{*} \mathrm{p}<10 \% ;{ }^{* *} \mathrm{p}<5 \%$; $* * * \mathrm{p}<1 \%$.

Fonte: elaborada pelos autores

No intento de identificar a relação entre o conservadorismo incondicional e as LPBTD, utilizando a variável LT como dependente, são observados os resultados apresentados na Tabela 7. A variável $\alpha_{4}$ apresentou significância estatística para o Brasil $(0,179)$ e Chile $(-0,048)$. O valor positivo $\left(\alpha_{4}>0\right)$, na estimativa para o Brasil, sugere menor existência do conservadorismo incondicional, enquanto que o sinal negativo $\left(\alpha_{4}<0\right)$, para o Chile, remete à maior presença dele nas informações reportadas pelas companhias. Desta forma, a hipótese $\mathrm{H}_{7}$, que supõe maior conservadorismo incondicional para as informações com as BTD positivas extremas, não foi rejeitada para o Chile, mas foi rejeitada para as companhias listadas no Brasil, em função do LT. Para as amostras dos demais países não houve resultados significantes.

Para a relação entre LPBTD e o conservadorismo condicional $\left(\alpha_{10}\right)$, com a variável LT como dependente, apenas o México $(-0,401)$ resultou em coeficiente com significância estatística. $O$ resultado estimado para o México acompanha sinal negativo $\left(\alpha_{10}<0\right)$. Sendo assim, sugere-se menor relação entre as LPBTD e o conservadorismo condicional nas informações contábeis reportadas pelas companhias listadas na bolsa de valores do México. $\mathrm{O}$ comportamento de menor relação com o conservadorismo condicional é esperado por meio da hipótese $\mathrm{H}_{8}$ que, neste caso, não foi rejeitada em função da variável LT como dependente.

Assim como a LPBTD, a LNBTD é observada em relação ao conservadorismo incondicional $\left(\alpha_{5}\right)$ tendo a variável LT como dependente. Com essa configuração, as estimativas foram, estatisticamente, significativas para Brasil $(0,201)$ e México $(0,142)$. O sinal positivo $\left(\alpha_{5}>0\right)$ encontrado no resultado dos dois países faz com que se tenha a percepção de menor presença do conservadorismo incondicional nessas amostras relacionadas às $L N B T D$. Portanto, a hipótese $\mathrm{H}_{9}$ foi rejeitada tanto para as companhias listadas na bolsa do Brasil, quanto para aquelas listadas na bolsa do México. Para a relação $L N B T D$ e

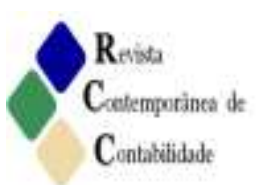


conservadorismo condicional $\left(\alpha_{11}\right)$, não houve estimativas estatisticamente significativas, não sendo possível avaliar a hipótese $\mathrm{H}_{10}$ para LT.

Para a América Latina, considerando a variável LT como dependente, os coeficientes apresentaram significância apenas para as variáveis relativas ao conservadorismo incondicional ( $\alpha_{4}$ e $\alpha_{5}$ ). Em relação à LPBTD e ao conservadorismo incondicional, o valor estimado na América Latina $(0,045)$, por ser de sinal positivo $\left(\alpha_{4}>0\right)$, sustenta a existência de menor conservadorismo incondicional na amostra em seu todo. $\mathrm{O}$ valor observado para a relação entre $L N B T D$ e o conservadorismo incondicional $(0,166)$ também foi positivo $\left(\alpha_{5}>0\right)$, sugerindo, então, menor relação entre a $L N B T D$ e o conservadorismo incondicional. As situações encontradas fazem com que as hipóteses $\mathrm{H}_{7}$ e $\mathrm{H}_{9}$ sejam rejeitadas para a América Latina na presença do LT. Em relação ao conservadorismo condicional não foram obtidos resultados para $\alpha_{10}$ e $\alpha_{11}$ que fossem estatisticamente significantes tendo a variável LT como dependente, não sendo aceitas as hipóteses $\mathrm{H}_{8}$ e $\mathrm{H}_{10}$.

A Equação 6 também foi aplicada utilizando-se a variável LAIR como dependente. Os resultados estimados, para identificar o conservadorismo incondicional em amostras com LPBTD $\left(\alpha_{4}\right)$, foram significativos para Brasil $(0,445)$ e Peru $(0,385)$, no nível de $1 \%$, e significativos para Argentina $(0,177)$ e Chile $(0,385)$, no nível de 5\%. Os resultados encontrados para Argentina, Brasil, Chile e Peru tiveram sinal positivo $\left(\alpha_{4}>0\right)$, ou seja, contrário ao esperado, o que leva à suposição de que as informações contábeis reportadas têm menores índices de conservadorismo incondicional. Desta forma, para o LAIR como variável dependente, a hipótese $\mathrm{H}_{7}$ foi rejeitada.

Os resultados obtidos para a relação entre LPBTD e conservadorismo condicional na presença das LPBTD, tendo a variável LAIR como dependente, foram significativos para o México $(-0,654)$ e Peru $(-1,233)$, no nível de $5 \%$. Devido ao sinal negativo $\left(\alpha_{10}<0\right)$ encontrado para a amostra referente aos dois países, estima-se menor relação entre LPBTD e conservadorismo condicional. Logo, a hipótese $\mathrm{H}_{8}$ não foi rejeitada para essas amostras tendo o LAIR como variável dependente.

Com a variável LAIR como dependente, para a relação entre $L N B T D$ e conservadorismo incondicional $\left(\alpha_{5}\right)$, foram identificados resultados significativos apenas para o Chile $(-0,127)$, no nível de $1 \%$. As estimativas encontradas para esse país foram acompanhadas de sinal negativo $\left(\alpha_{5}<0\right)$; estima-se, então, maior relação entre o conservadorismo incondicional e as $L N B T D$. Indo ao encontro do que foi especificado na hipótese $\mathrm{H}_{9}$, esta não foi rejeitada para o LAIR como variável dependente.

Para a relação entre as $L N B T D$ e o conservadorismo condicional, tendo a variável LAIR como dependente, a estimativa foi significativa apenas para a Argentina $(-0,909)$, no nível de significância de $10 \%$. O sinal negativo $\left(\alpha_{11}<0\right)$, que acompanha o valor encontrado, faz com que a hipótese $\mathrm{H}_{10}$ não seja rejeitada. Sugere-se, então, que as companhias argentinas têm menor nível de conservadorismo condicional. As demais amostras não apresentam significância estatística para essa observação.

Em relação à América Latina, considerando, então, a amostra em seu todo e utilizando a variável LAIR como dependente, a variável referente ao conservadorismo incondicional para LPBTD $\left(\alpha_{4}\right)$ foi significativa no nível de 1\%. O valor encontrado para a América Latina $(0,2834)$ tem sinal positivo $\left(\alpha_{4}>0\right)$, sendo contrário ao sinal esperado; neste contexto, a hipótese $\mathrm{H}_{7}$ é rejeitada, pois o resultado indica menor presença de conservadorismo incondicional nas informações reportadas na presença da LPBTD. Os valores estimados para a relação entre a $L N B T D$ e o conservadorismo incondicional não foram significativos para a 
América Latina.

Para a relação entre o conservadorismo condicional e a LPBTD $\left(\alpha_{10}\right)$, para a amostra relacionada à América Latina, o valor não foi significativo ao ter a variável LAIR como dependente. Quanto à relação entre a $L N B T D$ e o conservadorismo incondicional $\left(\alpha_{11}\right)$, foi estimado, para a América Latina $(0,180)$, valor positivo $\left(\alpha_{11}>0\right)$, resultando na rejeição da hipótese $\mathrm{H}_{10}$, tendo em vista que, para o LAIR sugere-se maior relação entre a $L N B T D$ e o conservadorismo condicional nos relatórios contábeis emitidos pelas companhias latinoamericanas. Esses resultados não permitem aceitar as hipóteses $\mathrm{H}_{7}, \mathrm{H}_{8}, \mathrm{H}_{9}$ e $\mathrm{H}_{10}$, quando a variável dependente é o LAIR.

Os resultados encontrados para as variáveis LNBTD E LPBTD são divergentes daqueles encontrados por Heltzer (2009). Este autor identificou maior conservadorismo incondicional no LT, quando a BTD é LPBTD, e conservadorismo incondicional no LAIR, quando a BTD é LNBTD. Os resultados encontrados por esse autor sugerem que a magnitude positiva ou negativa da BTD pode estar relacionada com a menor qualidade das informações contábeis. Esses resultados não foram confirmados nos países da América Latina.

\subsection{Resumo dos Resultados - América Latina}

$\mathrm{Na}$ Tabela 8 é apresentado um resumo dos resultados para os países da América Latina.

Tabela 8 - Resumo dos Resultados para a América Latina

\begin{tabular}{|l|c|c|}
\hline \multicolumn{1}{|c|}{ Hipótese investigada } & LAIR & LT \\
\hline $\begin{array}{l}\mathrm{H}_{1}: \text { As companhias listadas nas bolsas de valores de países da América Latina } \\
\text { apresentam relação positiva entre a BTD e o conservadorismo condicional. }\end{array}$ & Rejeitada & Rejeitada \\
\hline $\begin{array}{l}\mathrm{H}_{2}: \text { As companhias listadas nas bolsas de valores de países da América Latina } \\
\text { apresentam relação negativa entre a BTD e o conservadorismo incondicional. }\end{array}$ & Confirmada & Rejeitada \\
\hline $\begin{array}{l}\mathrm{H}_{3}: \text { As companhias listadas nas bolsas de valores de países da América Latina } \\
\text { apresentam relação positiva entre a BTDTE e o conservadorismo incondicional. }\end{array}$ & Rejeitada & Rejeitada \\
\hline $\begin{array}{l}\mathrm{H}_{4}: \text { As companhias listadas nas bolsas de valores de países da América Latina } \\
\text { apresentam relação negativa entre a BTDTE e o conservadorismo condicional. }\end{array}$ & Confirmada & Rejeitada \\
\hline $\begin{array}{l}\mathrm{H}_{5}: \text { As companhias listadas nas bolsas de valores de países da América Latina } \\
\text { apresentam relação positiva entre a BTDP e o conservadorismo condicional. }\end{array}$ & Rejeitada & Rejeitada \\
\hline $\begin{array}{l}\mathrm{H}_{6}: \text { As companhias listadas nas bolsas de valores de países da América Latina } \\
\text { apresentam relação negativa entre a BTDP e o conservadorismo incondicional. }\end{array}$ & Confirmada & Rejeitada \\
\hline $\begin{array}{l}\mathrm{H}_{7}: \text { As companhias listadas nas bolsas de valores de países da América Latina } \\
\text { apresentam relação positiva entre as LPBTD e o conservadorismo incondicional. }\end{array}$ & Rejeitada & Rejeitada \\
\hline $\begin{array}{l}\mathrm{H}_{8}: \text { As companhias listadas nas bolsas de valores de países da América Latina } \\
\text { apresentam relação negativa entre as LPBTD e o conservadorismo condicional. }\end{array}$ & Rejeitada & Rejeitada \\
\hline $\begin{array}{l}\mathrm{H}_{9}: \text { As companhias listadas nas bolsas de valores de países da América Latina } \\
\text { apresentam relação positiva entre as LNBTD e o conservadorismo incondicional. }\end{array}$ & Rejeitada & Rejeitada \\
\hline $\begin{array}{l}\mathrm{H}_{10}: \text { As companhias listadas nas bolsas de valores de países da América Latina } \\
\text { apresentam relação negativa entre as LNBTD e o conservadorismo condicional. }\end{array}$ & Rejeitada & Rejeitada \\
\hline
\end{tabular}

Definição das variáveis: LAIR é o lucro contábil antes do imposto de renda escalonado pelo valor da ação defasado; LT é o lucro tributável escalonado pelo valor da ação defasado; BTD é a BTD total; BTDTE é a BTD temporária; BTDTP é a BTD permanente; LNBTD é uma variável binária com valor igual a 1 quando se tem os valores mais elevados para a BTDNE; LPBTD é uma variável binária com valor igual a 1 quando se tem os valores mais elevados para a BTDPO.

Fonte: elaborada pelos autores 
Os resultados sugerem que a BTD total, temporária e permanente, não afeta o conservadorismo das demonstrações contábeis divulgadas (ver coluna LAIR). Porém, a BTD parece aumentar o conservadorismo incondicional do lucro tributável, sugerindo existência de gerenciamento no LT. Quando segregada a BTD, o aumento do conservadorismo incondicional do LT parece estar relacionado com a BTD permanente, enquanto o conservadorismo condicional do LT está relacionado com a BTD temporária.

Os extremos da BTD positiva e negativa (LPBTD e LNBTD) parecem reduzir o conservadorismo incondicional e aumentar o conservadorismo condicional das demonstrações contábeis publicadas (ver coluna LAIR). Esses resultados são similares àqueles encontrados por Heltzer (2009), exceto pelo fato de a LNBTD apresentar maior relação com o conservadorismo incondicional do LAIR e menor relação com o conservadorismo condicional e incondicional do LT no trabalho desse autor.

\section{Considerações Finais}

O objetivo da presente pesquisa foi analisar a relação existente entre os tipos de BTD e o conservadorismo contábil em países da América Latina. Especificamente, este trabalho examina se os tipos de BTD revelam informações sobre o conservadorismo das demonstrações financeiras. Acredita-se que as variações da BTD revelam informações sobre as variações no conservadorismo. No entanto, apenas Heltzer (2009) testou essa relação utilizando três tipos de BTD (total, positiva e negativa). Nesta pesquisa, são analisados 5 (cinco) tipos de BTD (BTD total, BTD temporária - BTDTE, BTD permanente - BTDTP, valores extremos de BTD positiva - $L P B T D$, valores extremos de BTD negativa - $L N B T D$ ). Para a realização do estudo, foram observadas companhias abertas listadas em países da América Latina, considerando o período entre 2004 e 2013.

Os resultados sugerem que o uso da BTD, para medir o conservadorismo das demonstrações contábeis, deve ser avaliado com cautela, uma vez que a relação entre a BTD e o conservadorismo contábil depende de uma série de fatores, como, por exemplo: tipos de BTD, tipos de conservadorismo, conservadorismo do resultado contábil ou fiscal. Para a BTD total, os resultados apontam redução do conservadorismo condicional (tanto no LT quanto no LAIR) na presença de maior BTD total nos países da América Latina. Esse resultado é contrário ao esperado, podendo sugerir menor qualidade da informação reportada.

Por outro lado, foi identificado um aumento no conservadorismo incondicional no lucro tributável e redução no lucro contábil, sugerindo maior gerenciamento no lucro tributável. De forma inesperada, a BTD temporária e a BTD permanente não se relacionaram positivamente com o conservadorismo incondicional, com LAIR ou LT como variáveis independentes. Porém a BTDTE está relacionada negativamente com o conservadorismo condicional, quando o LAIR é a variável dependente, o que pode sugerir menor qualidade das informações financeiras. Porém a BTDP está relacionada positivamente com o conservadorismo incondicional quando o LT é a variável dependente, o que pode sugerir gerenciamento tributário. Esses resultados indicam o tipo de BTD como relevante na identificação do conservadorismo contábil e que é importante observar aspectos do conservadorismo tanto no lucro contábil, quanto no lucro tributável.

Os resultados da pesquisa oferecem indícios que corroboram a hipótese teórica de que maiores valores de BTD estão relacionados com menor conservadorismo, uma vez que os valores extremos de BTD positiva e negativa não apresentaram relação positiva com o 
conservadorismo incondicional. Essa conclusão traz a origem do país (legalista ou não legalista) também como relevante na análise da relação entre a BTD e o conservadorismo. Enquanto Heltzer (2009), utilizando uma amostra de países legalistas e não legalistas, encontrou relação entre valores extremos de BTD negativa e o conservadorismo incondicional, nesta pesquisa esse fato não foi corroborado.

Ressalta-se que a amostra de companhias pertencentes a cinco países da América Latina não permite a generalização dos dados, apesar da representatividade dos países selecionados. Para pesquisas futuras sugere-se a investigação das possíveis relações entre conservadorismo e os tipos de BTD, aplicando outras metodologias além da de Basu (1997), bem como a inclusão de companhias de outros países que possibilitem a comparação entre países legalistas e não legalistas.

\section{Referências}

AHMED, K.; HENRY, D. Accounting conservatism and voluntary corporate governance mechanisms by Australian firms. Accounting \& Finance, v. 52, n. 3, p. 631-662, 2012.

AMARAL, J. V.; RICCIO, E. L.; SAKATA, M. C. G. Conservadorismo Contábil Ainda é Discutido? Revista Universo Contábil, v. 8, n. 1, p. 70-85, 2012.

ANDRÉ, P.; FILIP, A.; PAUGAM, L. Impact of Mandatory IFRS Adoption on Conditional Conservatism in Europe. Research Center. ESSEC Working Paper, n.1311, 2013.

ATWOOD, T. J.; DRAKE, M. S.; MYERS, L. A. Book-tax conformity, earnings persistence and the association between earnings and future cash flows. Journal of Accounting and Economics, v. 50, n. 1, p. 111-125, 2010.

BALL, R.; SHIVAKUMAR, L. Earnings quality in UK private firms: comparative loss recognition timeliness. Journal of accounting and economics, v. 39, n. 1, p. 83-128, 2005.

BALL, R; KOTHARI, S. P.; NIKOLAEV, V. V. Econometrics of the Basu asymmetric timeliness coefficient and accounting conservatism. Journal of Accounting Research, v. 51, n. 5, p. 1071-1097, 2013.

BASU, S. Conservatism Research: Historical Development and Future Prospects. China Journal of Accounting Research, v. 2, n. 1, p.1-20, jun., 2009.

BASU, S. Discussion of "Conditional and Unconditional Conservatism: Concepts and Modeling”. Review of Accounting Studies, v. 10, n. 2-3, p. 311-321, 2005.

BASU, S. The conservatism principle and the asymmetric timeliness of earnings. Journal of Accounting \& Economics, v. 24, p 3-37, 1997.

BEAVER, W. H.; RYAN, S. G. Conditional and unconditional conservatism: Concepts and modeling. Review of Accounting Studies, v. 10, n. 2-3, p. 269-309, 2005.

BERTIN, M. J.; MOYA, J. T. A. The effect of mandatory IFRS adoption on accounting conservatism of reported earnings Evidence from Chilean firms. Academia Revista Latinoamericana de Administración, v. 26, n.1, p. 139-169, 2013.

BRAGA, J. P. Configuração da estrutura de propriedade e conservadorismo. In: Congresso USP de Controladoria e Contabilidade, 13, 2013, São Paulo/SP. Anais... São Paulo, 
FEA/USP, 2013.

CHAN, K. H.; LIN, K. Z.; MO, P. L. Will a departure from tax-based accounting encourage tax noncompliance? Archival evidence from a transition economy. Journal of Accounting and Economics, v. 50, n. 1, p. 58-73, 2010.

COMPRIX, J.; GRAHAM. R. C.; MOORE, J. A. Empirical evidence on the impact of booktax differences on divergence of opinion among investors. Journal of the American Taxation Association, v. 33, n. 1, p. 57-78, 2011.

COSTA, P. S.; LOPES, A. B. Implicações da adoção das IFRS sobre as book-tax differences: o caso do Brasil. Editora: NEA. Alemanha, 2015.

CPC - Comitê de Pronunciamentos Contábeis. Estrutura Conceitual: para a elaboração e apresentação das demonstrações contábeis. 2011. Disponível em:

$<$ http://www.cpc.org.br/pronunciamentosIndex.php>. Acesso em: 20 abr. 2013.

DESAI, M. A. The degradation of reported corporate profits. Journal of Economic Perspectives, p. 171-192, 2005.

DESAI, M. A. The Divergence Between Book Income And Tax Income. In: POTERBA, J. M. Tax Policy and the Economy, v. 17, Cambridge: MIT Press, p.169-208, 2003.

DOUPNIK, T. S.; RICCIO, E. L. The influence of conservatism and secrecy on the interpretation of verbal probability expressions in the Anglo and Latin cultural areas. The International Journal of Accounting, v. 41, n. 3, p. 237-261, 2006.

FÁVERO, L. P.; BELFIORE, P.; SILVA, F. L.; CHAN, B. L. Análise de dados: modelagem multivariada para tomada de decisões. Rio de Janeiro: Elsevier, 2009

FERREIRA, F. R.; MARTINEZ, A. L.; COSTA, F. M.; PASSAMANI, R. R. Book-Tax Differences e Gerenciamento de Resultados no Mercado de Ações do Brasil. Revista de Administração de Empresas, RAE, São Paulo, v. 52, n. 5, set./out., p. 488-501, 2012.

FILIPIN, R.; TEIXEIRA, S. A.; BEZERRA, F. A.; CUNHA, P. R. Análise do nível de conservadorismo condicional das empresas brasileiras listadas na BM\&FBOVESPA após a adoção dos IFRS. Revista Contabilidade e Controladoria-RC\&C, v. 4, n. 2, 2012.

FORMIGONI, H.; ANTUNES, M. T. P.; PAULO, E. Diferença entre o lucro contábil e lucro tributável: uma análise sobre o gerenciamento de resultados contábeis e gerenciamento tributário nas companhias abertas brasileiras. BBR Brazilian Business Review, v. 6, n. 1, p. 44-61, 2009.

FRANK, M. M.; LYNCH, L. J.; REGO, S. O. Tax reporting aggressiveness and its relation to aggressive financial reporting. The Accounting Review, v. 84, n. 2, p. 467-496, 2009.

GARBRECHT, G. T.; TROMBELLI, R. D.; COLAUTO, R. D.; SCHERER, L.M.

Conservadorismo condicional ex post a Lei 11.638/07: um estudo sobre a qualidade do lucro contábil em empresas listadas na BM\&FBOVESPA. In: Congresso USP de Controladoria e Contabilidade, 12, 2012, São Paulo/SP. Anais... São Paulo, FEA/USP, 2012.

GRAY, Sidney J. Towards a theory of cultural influence on the development of accounting systems internationally. Abacus, v. 24, n. 1, p. 1-15, 1988.

HANLON, M. The persistence and pricing of earnings, accruals, and cash flows when firms 
have large book-tax differences. The Accounting Review, v. 80, n. 1, p. 137-166, 2005.

HANLON, M.; MAYDEW, E. L. Book-Tax Conformity: Implications for Multinational Firms. National Tax Journal, v. 62, n. 1, mar., 2009.

HANLON, M.; MAYDEW, E. L.; SHEVLIN, T. An unintended consequence of book-tax conformity: A loss of earnings informativeness. Journal of Accounting and Economics, v. 46, n. 2, p. 294-311, 2008.

HANLON, M; HEITZMAN, S. A Review of Tax Research. Journal of Accounting and Economics, v. 50, n. 2, p. 127-178, 2010.

HELTZER, Wendy. Conservatism and book-tax differences. Journal of Accounting, Auditing \& Finance, v. 24, n. 3, p. 469-504, 2009.

HOU, Q.; JIN, Q.; WANG, L. Mandatory IFRS adoption and executive compensation: Evidence from China. China Journal of Accounting Research, v. 7, n. 1, p. 9-29, 2014.

HU, J.; LI, A. Y.; ZHANG, F. F. Does accounting conservatism improve the corporate information environment?.Journal of International Accounting, Auditing and Taxation, v. 23, n. 1, p. 32-43, 2014

IASB - International Accounting Standards Board. Conceptual Framework. 2011. Disponível em: http://www.ifrs.org/Current-Projects/IASB-Projects/ConceptualFramework/Pages/Conceptual-Framework-Summary.aspx. Acesso em: 28 mai 2014.

IATRIDIS, G. E. Accounting disclosures, accounting quality and conditional and unconditional conservatism. International Review of Financial Analysis, v. 20, n. 2, p. 88$102,2011$.

IFRS. International Financial Reporting Standards, 2014. Analysis of the IFRS jurisdictional profiles Disponível em: $<$ http://www.ifrs.org/Use-around-theworld/Pages/Analysis-of-the-IFRS-jurisdictional-profiles.aspx>. Acesso em: 27 mar. 2014.

KVAAL, E.; NOBES, C. International differences in IFRS policy choice: a research note. Accounting and Business Research, v.40, n. 2, p. 173-187, 2010.

LEV, B.; NISSIM, D. Taxable income, future earnings, and equity values. The Accounting Review, v. 79, n. 4, p. 1039-1074, 2004.

LI, D. Does auditor tenure affect accounting conservatism? Further evidence. Journal of Accounting and Public Policy, v. 29, n. 3, p. 226-241, 2010.

MILLS, L. F.; PLESKO, G. A. Bridging the reporting gap: a proposal for more informative reconciling of book and tax income. National Tax Journal, p. 865-893, 2003.

NAKAO, S. H. A adoção de IFRS e o Legado da Conformidade Mandatória ContábilFiscal. Tese (Livre Docência) - Faculdade de Economia, Administração e Contabilidade de Ribeirão Preto, Universidade de São Paulo, Ribeirão Preto. 2012. Disponível em: $<$ http://www.teses.usp.br/teses/disponiveis/livredocencia/96/tde-31012014-140349/en.php>. Acesso em 17 mar. 2014.

PHAM, H. M.; SHOOK, C.; MYERS, J. Accounting Conservatism In International Financial Reporting Standards And U.S. Generally Accepted Accounting Principles. INQUIRY. v. 10, p. 86-93, 2009. 
PHILLIPS, J.; PINCUS, M.; REGO, S. O. Earnings management: new evidence based on deferred tax expense. The Accounting Review. v. 78, n. 2, p. 491-521, 2003.

PIOT, C.; DUMONTIER, P.; JANIN, R. IFRS consequences on accounting conservatism within Europe: the role of Big 4 auditors. 2011. Disponível em: http://ssrn.com/abstract=1754504. Acesso em: 15 set. 2014.

PRATT, J. Financial Accounting in an Economic Context. 8. ed. Hoboken: John Wiley \& Sons, 2011.

REVSINE, L.; COLLINS, D.; JOHNSON, W. Financial Reporting \& Analysis. 3.ed. NJ: Prentice Hall, 2005.

TANG, T. H; FIRTH, M. Can book-tax differences capture earnings management and tax management? Empirical evidence from China. The International Journal of Accounting, v. 46, n. 2, p. 175-204, 2011.

WAHAB, N. S. A.; HOLLAND, K. The persistence of book-tax differences. The British Accounting Review, v. 47, n. 4, p. 339-350, 2015.

WATTS, R. L. Conservatism in accounting part I: Explanations and Implications.

Accounting horizons, v. 17, n. 3, p. 207-221, 2003a.

WATTS, R. L.. A proposal for Research on Conservatism. Maio 1993. Disponível em: < http://papers.ssrn.com/ >. Acesso em: 05 set. 2013.

WATTS, Ross L. Conservatism in accounting part II: evidence and research opportunities. Accounting horizons, v. 17, n. 4, p. 287-301, 2003 b.

WEBER, D. P. Do Analysts and Investors Fully Appreciate the Implications of Book-Tax Differences for Future Earnings? Contemporary Accounting Research, v. 26, n. 4, p. 1175 1206, 2009.

WILSON, R J. An examination of corporate tax shelter participants. The Accounting Review, v. 84, n. 3, p. 969-999, 2009.

WORLDBANK. The World Bank. Countries. Disponível em http://www.worldbank.org/. Acesso em 05 jul. 2014. 